\title{
Effects of Soil-Foundation-Interaction on the Seismic Response of a Cooling Tower by 3D-FEM Analysis
}

\author{
Francesco Castelli ${ }^{1}\left(\mathbb{D}\right.$, Salvatore Grasso ${ }^{2}\left(\mathbb{D}\right.$, Valentina Lentini ${ }^{1, *}$ and Maria Stella Vanessa Sammito ${ }^{2}$ \\ 1 Faculty of Engineering and Architecture, University "Kore" of Enna, 94100 Enna, Italy; \\ francesco.castelli@unikore.it \\ 2 Department of Civil Engineering and Architecture, University of Catania, 95124 Catania, Italy; \\ sgrasso@dica.unict.it (S.G.); mariastella.sammito@phd.unict.it (M.S.V.S.) \\ * Correspondence: valentina.lentini@unikore.it
}

Citation: Castelli, F.; Grasso, S.; Lentini, V.; Sammito, M.S.V. Effects of Soil-Foundation-Interaction on the Seismic Response of a Cooling Tower by 3D-FEM Analysis. Geosciences 2021, 11, 200. https://doi.org/ 10.3390 /geosciences 11050200

Academic Editors: Enrico Priolo and Jesus Martinez-Frias

Received: 13 December 2020

Accepted: 30 April 2021

Published: 3 May 2021

Publisher's Note: MDPI stays neutral with regard to jurisdictional claims in published maps and institutional affiliations.

Copyright: (c) 2021 by the authors. Licensee MDPI, Basel, Switzerland. This article is an open access article distributed under the terms and conditions of the Creative Commons Attribution (CC BY) license (https:// creativecommons.org/licenses/by/ $4.0 /)$.

\begin{abstract}
This paper reports on the results of soil-foundation numerical modelling and the seismic response of a cooling tower founded on piles of a petrochemical facility located in the city of Augusta (Sicily, Italy). The city was affected in the past by some destructive earthquakes (1693, 1848, and 1990) that damaged a large territory of Southeastern Sicily, which was characterized by a very high seismic hazard. With this aim, the paper reports the FEM modelling of the seismic behaviour of the coupled soil-structure system. To determine the soil profile and the geotechnical characteristics, laboratory and in situ investigations were carried out in the studied area. The seismic event occurred in January 1693 and has been chosen as a scenario earthquake. Moreover, a parametric study with different input motions has also been carried out. A Mohr-Coulomb model has been adopted for the soil, and structural elements have been simulated by means of an elastic constitutive model. Two different vertical alignments have been analysed, considering both the free-field condition and the soil-structure interaction. The dynamic response has been investigated in terms of accelerations, response spectra, and amplification functions. The results have also been compared with those provided by Italian technical regulations. Finally, the seismic response of the coupled soil-structure system has been further examined in terms of peak bending moments along the pile foundation, emphasizing the possibility of a kinematic interaction on piles induced by the seismic action.
\end{abstract}

Keywords: petrochemical equipment; geotechnical characterization; coupled soil-structure system; FEM 3D analysis

\section{Introduction}

Petrochemical facilities are highly vulnerable to earthquakes, as shown by past seismic events like Kobe (Japan, 1995), Izmit (Turkey, 1999), Gujarat (India, 2001), and Tokachi-Oki (Japan, 2003).

In an industrial plant, a seismic event can cause not only economic impacts due to the interruption of the production cycle, but also casualties as a consequence of components collapsing, explosions, fires, and a release of toxic substances [1,2]. In addition, the collapse of an apparatus can induce the simultaneous damage of other apparatuses, triggering an uncontrolled domino effect $[1,3]$.

To evaluate the seismic vulnerability of petrochemical facilities, several codes and guidelines are used. Many of these codes have been developed primarily for building design and generally offer insufficiently detailed guidelines for the design and the evaluation of structures commonly found in petrochemical facilities. Consequently, many petrochemical operating companies have developed their own internal standards and guidelines for addressing the seismic design and evaluation issues.

In Italy, about one-third of relevant risk plants are located in medium to high seismic areas [3]. For this reason, several research studies were carried out with the aim to analyze the seismic responses of components in industrial process plants [4]. 
Structures found in petrochemical facilities fall into two main categories: building structures and non-building structures, respectively. Within non-building structures, two sub-categories are defined according to structural characteristics: non-building structures similar to buildings and non-building structures dissimilar to buildings. In addition, certain equipment and anchorage design requirements in a petrochemical facility fall under the category of "subsystem" rather than structures.

In this context, the present study was addressed by considering the specific seismicrelated aspects of petrochemical facility design, evaluation, and operations, providing a discussion of seismic design philosophy and the general intent of seismic design provisions. With this aim, the research examines the aspects related to seismic hazards and geotechnical issues, such as local site effects as well as the dynamic interaction among the soil, the foundation, and the superstructure.

The first step is represented by the definition of seismic hazards. The study also includes the methodology for performing seismic analysis of petrochemical facilities in order to obtain seismically induced loads. This is applicable to structural systems or subsystems to be used either in a new design or in evaluating existing facilities.

The seismic analysis of structures can be performed using the Equivalent Lateral Force Procedure. It determines the seismic loads by means of static methods. However, structures that have significant irregularities in shape, mass, or stiffness require a dynamic analysis, which can be used for all petrochemical facility structures [5].

The ground motion to be applied in a dynamic analysis is defined in terms of acceleration time-histories. The seismic response of structures depends on many factors, such as local site effects and a Dynamic Soil-Foundation-Structure Interaction. Site effects can lead to a significant alteration of the seismic action [6-8].

In the paper, a FEM analysis was carried out to investigate the soil-foundationinteraction and the seismic response of a typical petrochemical apparatus. For this purpose, several 2D-dimensional or 3D-dimensional numerical codes can be used employing different constitutive models.

Zhang et al. [9] implemented the Domain Reduction Method (DRM) and PerfectlyMatched-Layers (PMLs) in ABAQUS. They showed that the coupled DRM-PML technique is a key analysis tool for soil-structure interaction problems.

Esmaeilzadeh Seylabi et al. [10] explored the capabilities of calibrated equivalent linear soil models in capturing the seismic response of buried box structures, as observed in centrifuge tests. Massimino et al. [11] evaluated the seismic response of a soil-building system by means of an ADINA code and by using equivalent viscoelastic constitutive models for the soil and the structure.

Castelli et al. [12] investigated the response of singles pile to kinematic seismic loading using the computer program SAP2000. Kavitha et al. [13] analyzed a single concrete pile embedded in various types of soil subjected to a simple, harmonic, dynamic load. They investigated the influence of soil-structure interactions on the structural behaviour of the pile using PLAXIS 3D.

Finally, Deghoul et al. [14] studied the behaviour of pile-supported wharf embedded in rock dike using PLAXIS2D code. They applied three soil constitutive models in order to study the influence of the soil constitutive models on the seismic analysis. The models used were a linear-elastic perfectly plastic model (MC model), an elastoplastic model with isotropic hardening (HS model), and the hardening soil model with an extension to the small-strain stiffness (HSS model).

The study focuses on investigating the dynamic soil-foundation-interaction of a petrochemical component, i.e., a cooling tower founded on piles located in a petrochemical facility in Augusta (Sicily, Italy). The seismic response of the fully-coupled system has been performed by using PLAXIS 3D-dimensional finite element software.

Results are presented in terms of accelerations, response spectra, and amplification functions. Moreover, the seismic response of the coupled soil-foundation system has been 
further investigated in terms of peak bending moments along the piles, emphasizing the possibility of a kinematic interaction effect on piles induced by the seismic action.

\section{Case Study}

\subsection{Geology and Seismicity of Area}

The city of Augusta is located on the eastern coast of Sicily (Italy), which is an area subjected to high seismic risk. The city borders Catania to the north and Siracusa to the south.

The study area forms part of the Hyblean Plateau, which represents a contact area between the Eurasian and African regions. The thickness of the deposits varies between 50 and $300 \mathrm{~m}$. The upper part consists of recent alluvial soil that overhangs Pleistocene marine clay, called Augusta blue-grey clay [15]. Figure 1 shows the geological sketch map of the Hyblean Plateau.

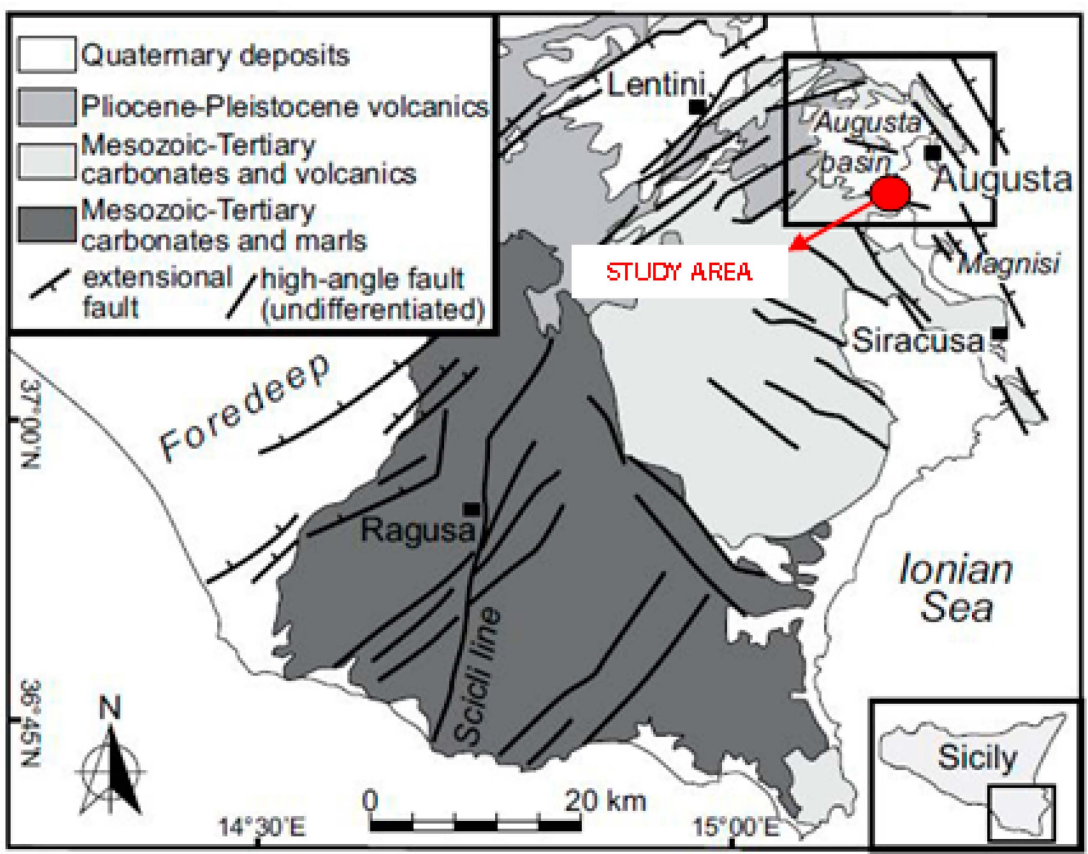

Figure 1. Geological sketch map of the Hyblean Plateau and adjacent fore deep area (After Di Martire et al. [16], modified).

The city has been destroyed by several disastrous earthquakes with an MCS intensity from VI to X (Figure 2).

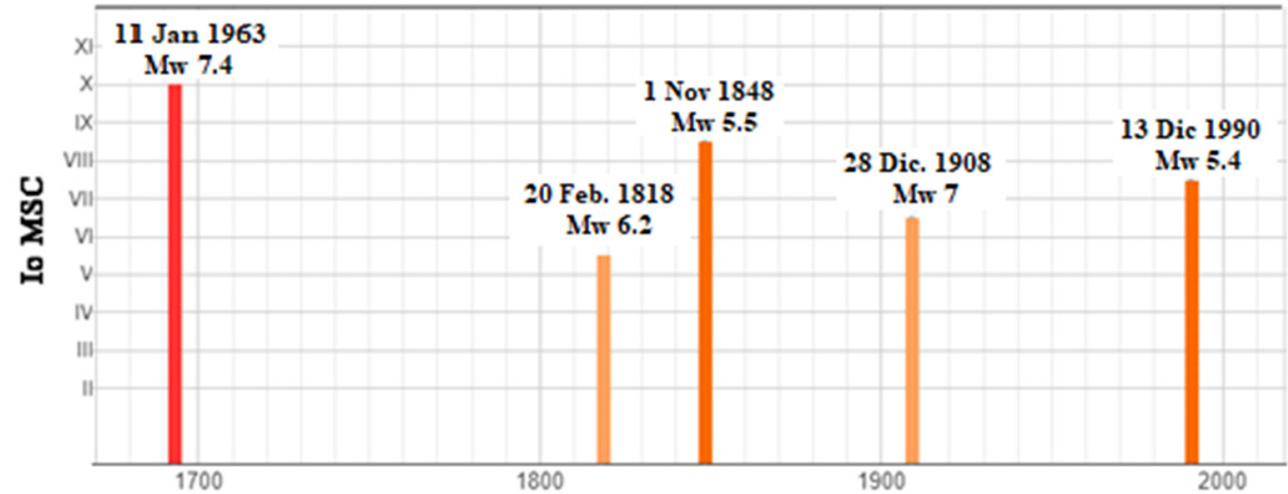

Figure 2. Timeline of earthquakes in the city of Augusta (After Locati et al. [17], modified, INGV database). 
The earthquake on 11 January 1693, known as "Val di Noto earthquake," struck a vast territory of Southeastern Sicily. It had an estimated magnitude of 7.4 on the moment magnitude scale and caused the partial, and, in many cases, total, destruction of 57 cities and 60,000 casualties [18-20].

The Etna earthquake that took place on 20 February 1818 caused moderate damage, but its effects were noticed over a vast area [21]. Some localities of Southeastern Sicily were shaken by the 1848 earthquake. The largest damage was observed in Augusta, where almost two-thirds of the buildings collapsed [22].

On December 1908, a devastating earthquake occurred along the Strait of Messina between the eastern tip of Sicily and the western tip of Calabria in Southern Italy. The greatest damage was experienced near the Strait of Messina. In Augusta, the violence reached VI-VII degrees on the Mercalli scale.

In the studied area, a large number of buildings exhibited fierce damage or collapsed due to the earthquake of 13 December 1990. Although the shock was of a moderate magnitude $\left(\mathrm{M}_{\mathrm{W}}=5.4\right)$, it caused deaths, injuries, and widespread damage due to the soft-soil conditions and construction deficiencies [23].

The seismic event that occurred in January 1693 has been chosen as the scenario earthquake. Figure 3 shows the intensity map for the 1693 earthquake.

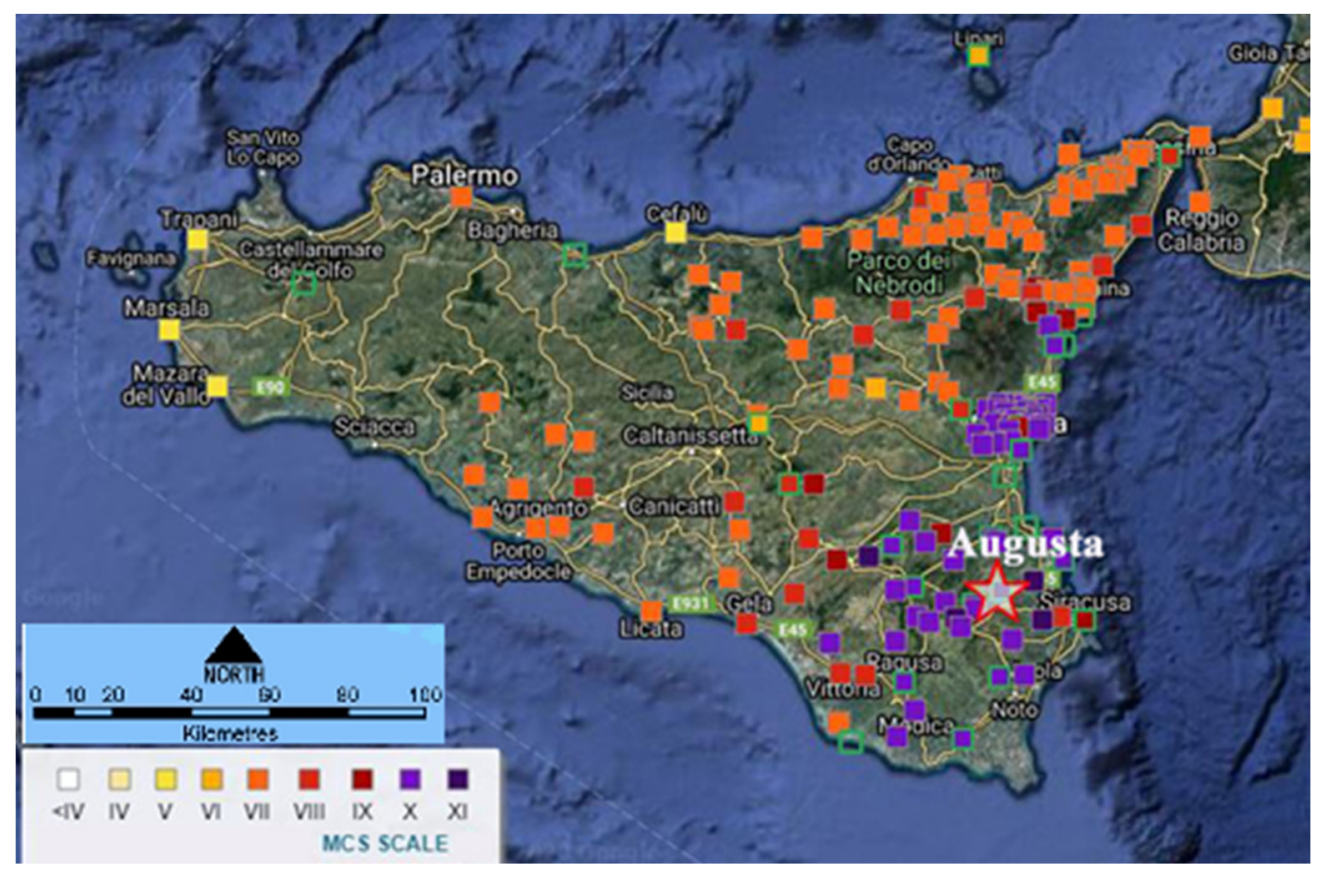

Figure 3. Intensity map. Earthquake of 11 January, 1693 (After Guidoboni et al. [24,25], modified, INGV database).

\subsection{Geotechnical Soil Properties}

The industrial district of Augusta is located on a flat area of the coastal hinterland. The area faces the Gulf of Augusta and consists of production facilities, including mainly petrochemical and cement factories (Figure 4). 


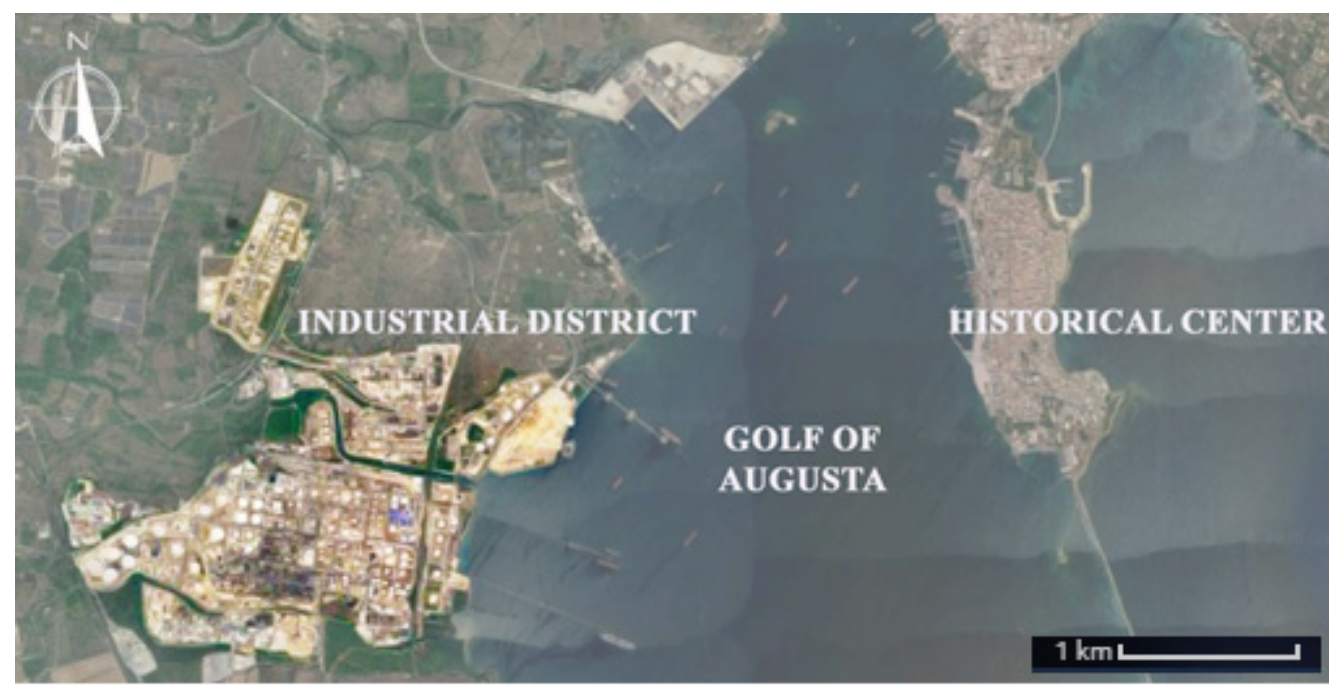

Figure 4. Layout of the studied area (After Google Maps, modified).

To evaluate the geotechnical characteristics of soil, the following in situ and laboratory tests were performed in the study area: no. 4 Boreholes, no. 4 Down-Hole Tests, no. 3 Direct Shear Tests, no. 5 Resonant Column Tests, no. 5 Cyclic Loading Torsional Shear Tests, no. 1 Cyclic Triaxial Test, and no. 3 Triaxial Unconsolidated Undrained Compression Tests. The locations of the boreholes, driven to a depth of $30 \mathrm{~m}$, are reported in Figure 5.

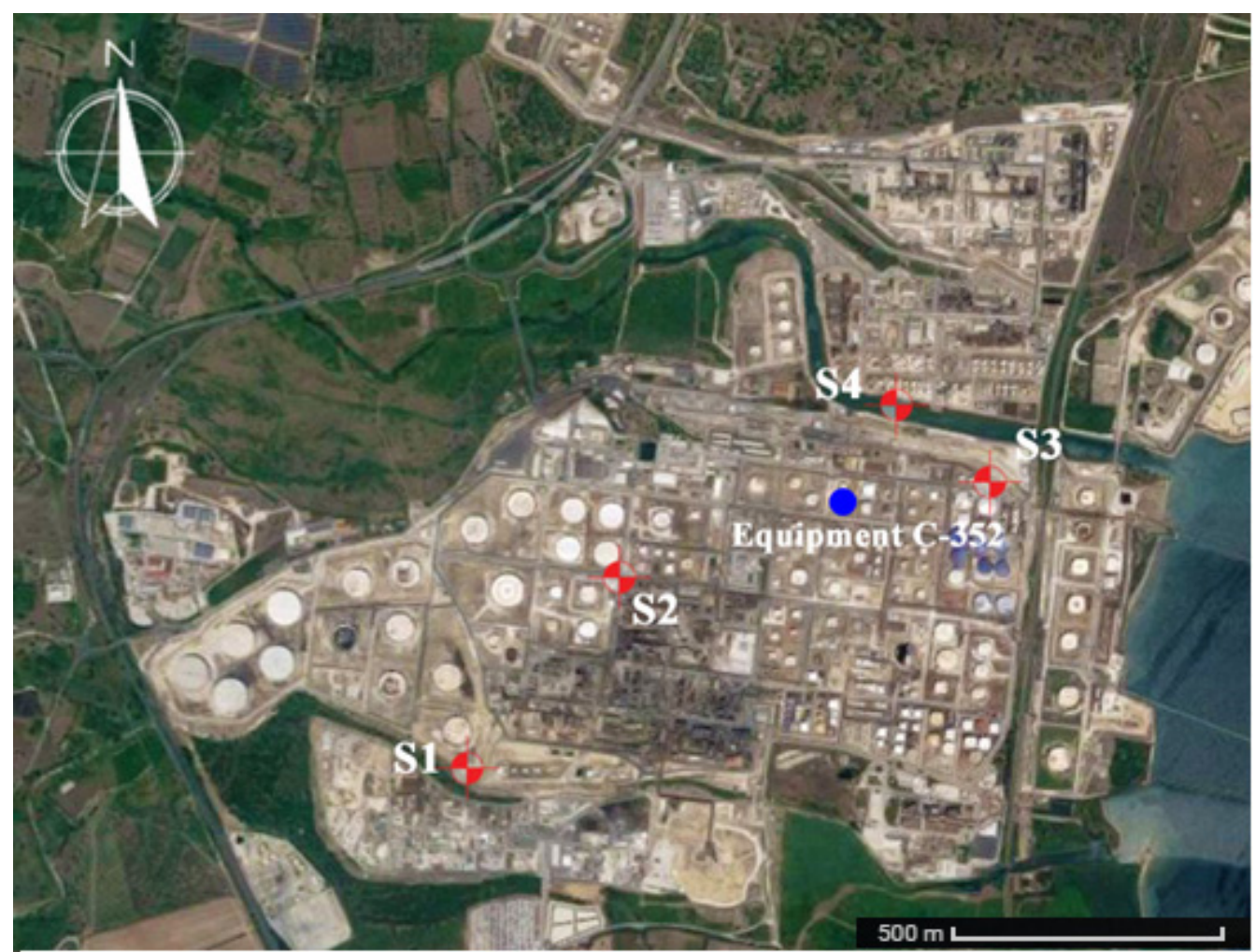

Figure 5. Location of boreholes (S1-S4) in the studied area (After Google Maps, modified).

The results of the boreholes are as follows.

- $\quad$ S1: backfill (0.00-2.00 m depth), calcarenites (2.00-2.40 $\mathrm{m}$ depth), yellow quartz sand (2.40-2.80 m depth), sandy silty clay (2.80-5.00 $\mathrm{m}$ depth), clayey sand (5.00-5.80 m depth), calcarenites (5.80-7.40 m depth), yellow quartz sand (7.40-9.70 m depth), and marly clay (9.70-30.00 m depth). 
- $\quad$ S2: backfill (0.00-1.00 m depth), sandy calcarenites and quartz sand (1.00-4.00 m depth), sandy clay (4.00-6.00 $\mathrm{m}$ depth), clayey sand (6.00-8.50 $\mathrm{m}$ depth), sandy clay (8.50-9.70 m depth), sandy silty clay (9.70-15.50 m depth), and marly clay (15.50-30.00 m depth).

- $\quad$ S3: backfill (0.00-1.00 m depth), calcarenites (1.00-1.40 m depth), calcarenite sands and gravel sand (1.40-2.90 m depth), calcarenites and yellow calcarenite sands $(2.90-4.40 \mathrm{~m}$ depth), brown silty clayey sand (4.40-8.50 m depth), yellow gravel sand (8.50-10.00 m depth), calcarenites (10.00-10.50 $\mathrm{m}$ depth), yellow gravel sand (10.50-12.00 $\mathrm{m}$ depth), clayey sand (12.00-12.60 m depth), sandy clay (12.60-13.50 $\mathrm{m}$ depth), and marly clay (13.50-30.00 m depth).

- S4: backfill (0.00-3.00 m depth), brown sandy-silty alluvial deposits (3.00-8.00 m depth), sandy alluvial deposits with included volcanic and calcarenite stones (8.00-18.00 m depth), and blue-grey clay (18.00-30.00 m depth).

The water table lies around $11 \mathrm{~m}$ below the ground surface. The boreholes were equipped for the execution of the Down Hole tests. In Figure 6, the shear and compression wave velocities are shown against the depth, for borehole S4, as an example.

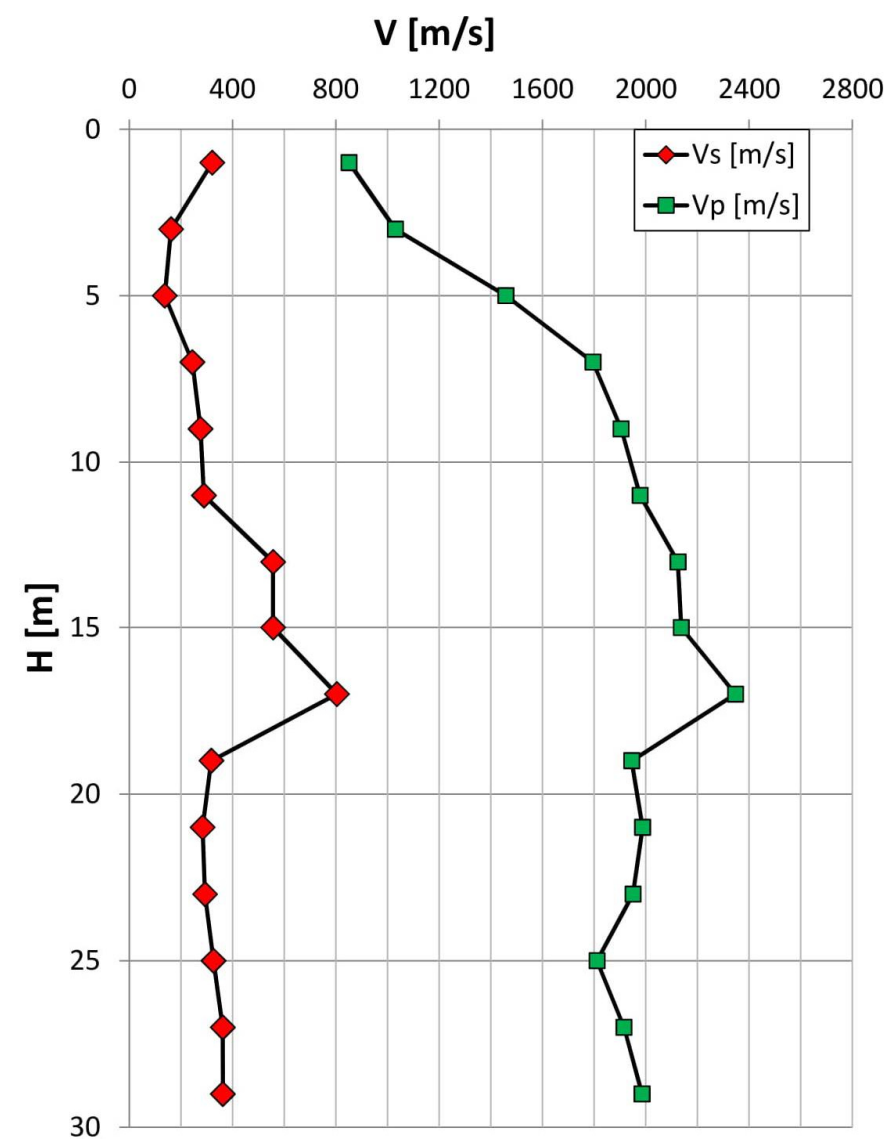

Figure 6. $\mathrm{V}_{\mathrm{s}}$ and $\mathrm{V}_{\mathrm{p}}$ from the Down Hole test (borehole S4).

The investigation reached a depth of $30 \mathrm{~m}$. The $\mathrm{V}_{\mathrm{S}}$ values ranged from 160 to $360 \mathrm{~m} / \mathrm{s}$. Higher values were reported for depths between 11 and $19 \mathrm{~m}$.

The dynamic Poisson ratio variation $(v)$ with depth, obtained from the DH test (borehole S4), is reported in Figure 7. The $v$ values range from 0.417 to 0.496 . 




Figure 7. Poisson ratio from the Down Hole test (borehole S4).

In addition to in situ investigations, laboratory tests were carried out on undisturbed samples, as reported in Table 1.

Table 1. List of soil samples.

\begin{tabular}{cccc}
\hline N. & Borehole & Name & Depth [m] \\
\hline 1 & S1 & C1 & $4.50-5.00$ \\
2 & S1 & C2 & $13.00-13.50$ \\
3 & S2 & C1 & $11.40-11.90$ \\
4 & S2 & C2 & $20.00-20.50$ \\
5 & S3 & C1 & $14.00-14.50$ \\
6 & S3 & C2 & $20.40-20.90$ \\
7 & S4 & C1 & $2.00-2.50$ \\
8 & S4 & C2 & $4.00-4.50$ \\
9 & S4 & C3 & $18.00-18.50$ \\
10 & S4 & C4 & $22.00-22.60$ \\
\hline
\end{tabular}

Based on the laboratory tests, index properties and strength parameters of the deposits are reported in Table 2.

Shear modulus $\mathrm{G}$ and damping ratio $\mathrm{D}$ were obtained from resonant column tests (RCT) and cyclic loading torsional shear tests (CLTST) performed by means of a resonant column/cyclic loading torsional shear apparatus. The same specimen was first subject to $\mathrm{RCT}$, and then to CLTST, after a rest period of $24 \mathrm{~h}$ with opened drainage [26-29].

Values of shear modulus G [MPa] and damping ratio D [\%] versus $\gamma$ [\%], for S1C1, S4C1, and S4C3, as examples, are reported in Figures 8-10. 
Table 2. Geotechnical properties.

\begin{tabular}{ccccccccccc}
\hline Samples & $\begin{array}{c}\gamma \\
{\left[\mathbf{k N} / \mathbf{m}^{3}\right]}\end{array}$ & $\begin{array}{c}\gamma_{\mathbf{s}} \\
{\left[\mathbf{k N} / \mathbf{m}^{3}\right]}\end{array}$ & $\begin{array}{c}\mathbf{w}_{\mathbf{n}} \\
{[\mathbf{\%}]}\end{array}$ & $\begin{array}{c}\mathbf{w}_{\mathbf{l}} \\
{[\mathbf{\%}]}\end{array}$ & $\begin{array}{c}\mathbf{w}_{\mathbf{p}} \\
{[\mathbf{\%}]}\end{array}$ & $\begin{array}{c}\mathbf{I}_{\mathbf{P}} \\
{[\mathbf{\%}]}\end{array}$ & $\mathbf{I}_{\mathbf{C}}$ & $\begin{array}{c}\mathbf{c}^{\prime} \\
{[\mathbf{k P a}]}\end{array}$ & $\begin{array}{c}\boldsymbol{\varphi}^{\prime} \\
{\left[{ }^{\circ}\right]}\end{array}$ & $\begin{array}{c}\mathbf{c}_{\mathbf{u}} \\
{[\mathbf{k P a}]}\end{array}$ \\
\hline S1C1 & 18.44 & 25.12 & 29.27 & 66.18 & 32.20 & 33.99 & 1.09 & - & - \\
S1C2 & 18.74 & 25.00 & 34.28 & 57.15 & 28.03 & 29.12 & 0.79 & - & - \\
S2C1 & 18.84 & 25.02 & 31.22 & 66.84 & 30.32 & 36.52 & 0.98 & - & - \\
S2C2 & 18.64 & 25.11 & 32.71 & 72.33 & 31.05 & 41.28 & 0.96 & - & - \\
S3C1 & 18.74 & 26.09 & 24.34 & 37.24 & 23.37 & 13.88 & 0.93 & - & - \\
S3C2 & 18.93 & 25.11 & 31.14 & 59.44 & 24.89 & 34.55 & 0.82 & - & - \\
S4C1 & 17.9 & 24.5 & 29.3 & 61.7 & 32.2 & 29.5 & 1.1 & - & - \\
S4C2 & 17.9 & 25.4 & 43.2 & 54.0 & 32.8 & 21.2 & 0.5 & 24 & - & - \\
S4C3 & 18.4 & 24.4 & 32.6 & 69.4 & 38.3 & 31.1 & 1.2 & 58 & 24 \\
S4C4 & 18.7 & 26.5 & 33.7 & 69.5 & 27.9 & 41.6 & 0.9 & 44 & 25 & 114 \\
\hline
\end{tabular}

(a)

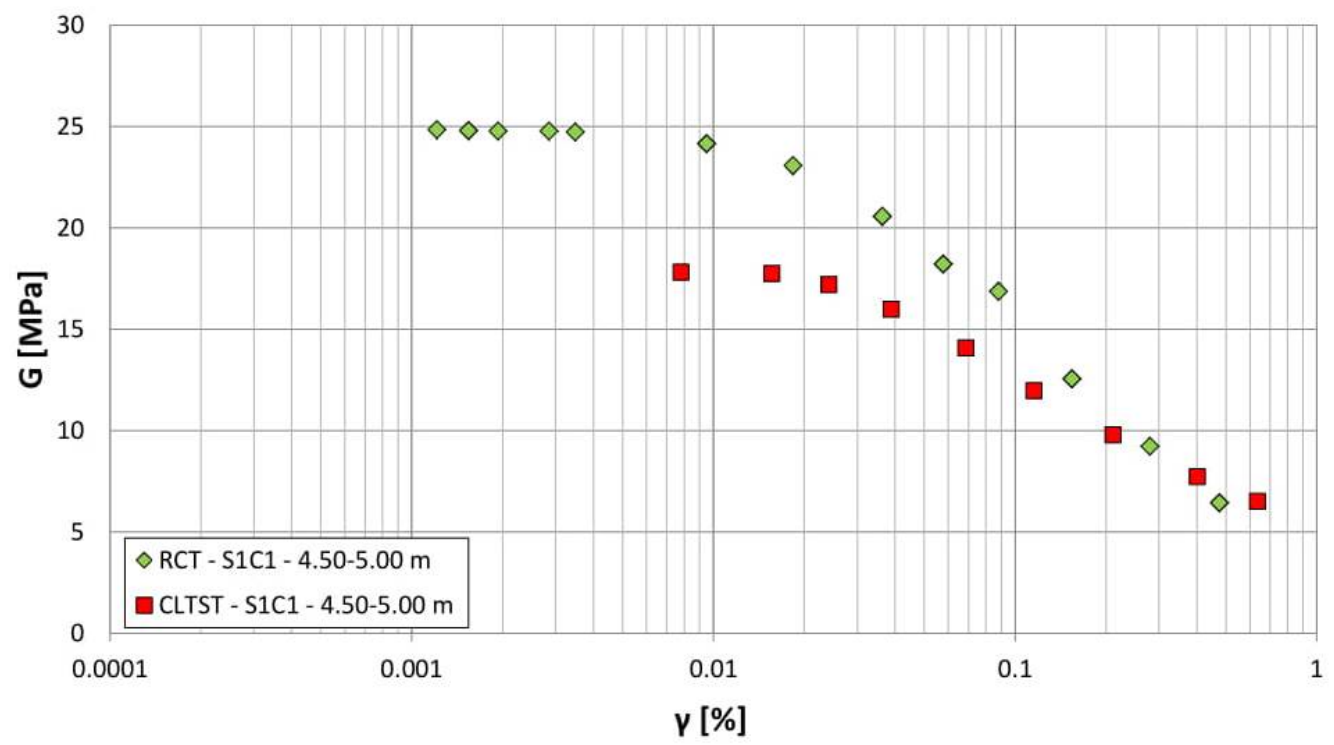

(b)

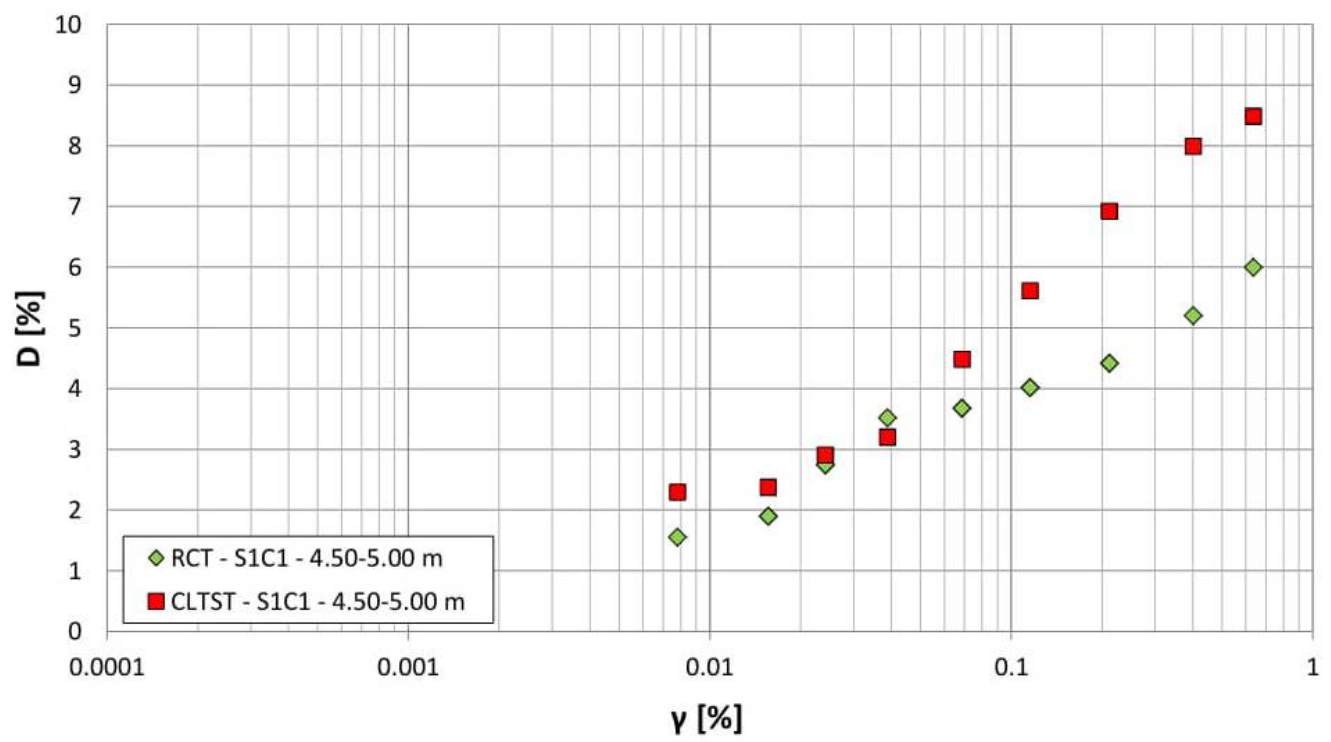

Figure 8. (a) G [MPa] versus $\gamma[\%]$ curves. (b) D [\%] versus $\gamma$ [\%] curves (for the $\mathrm{S} 1 \mathrm{C} 1$ soil sample). 


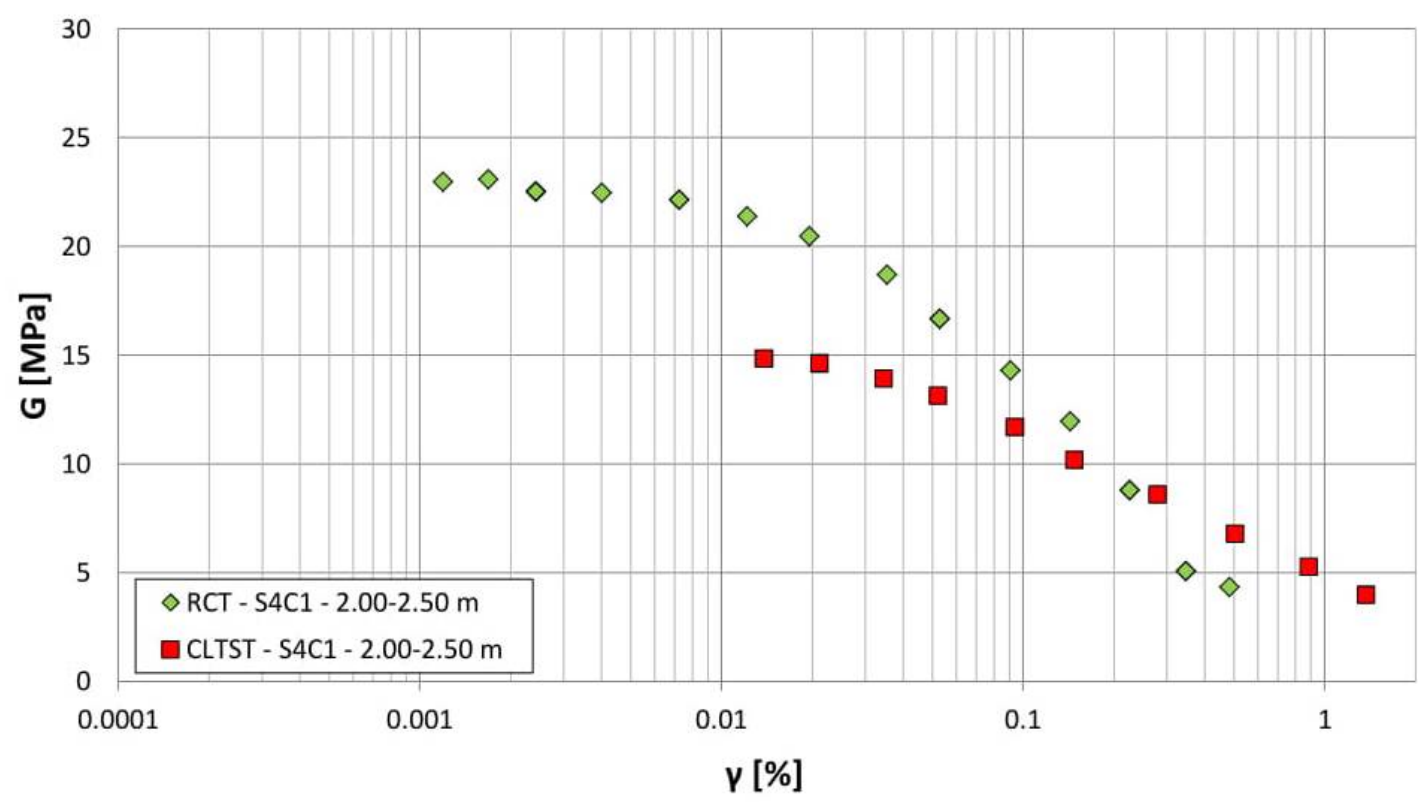

(b)

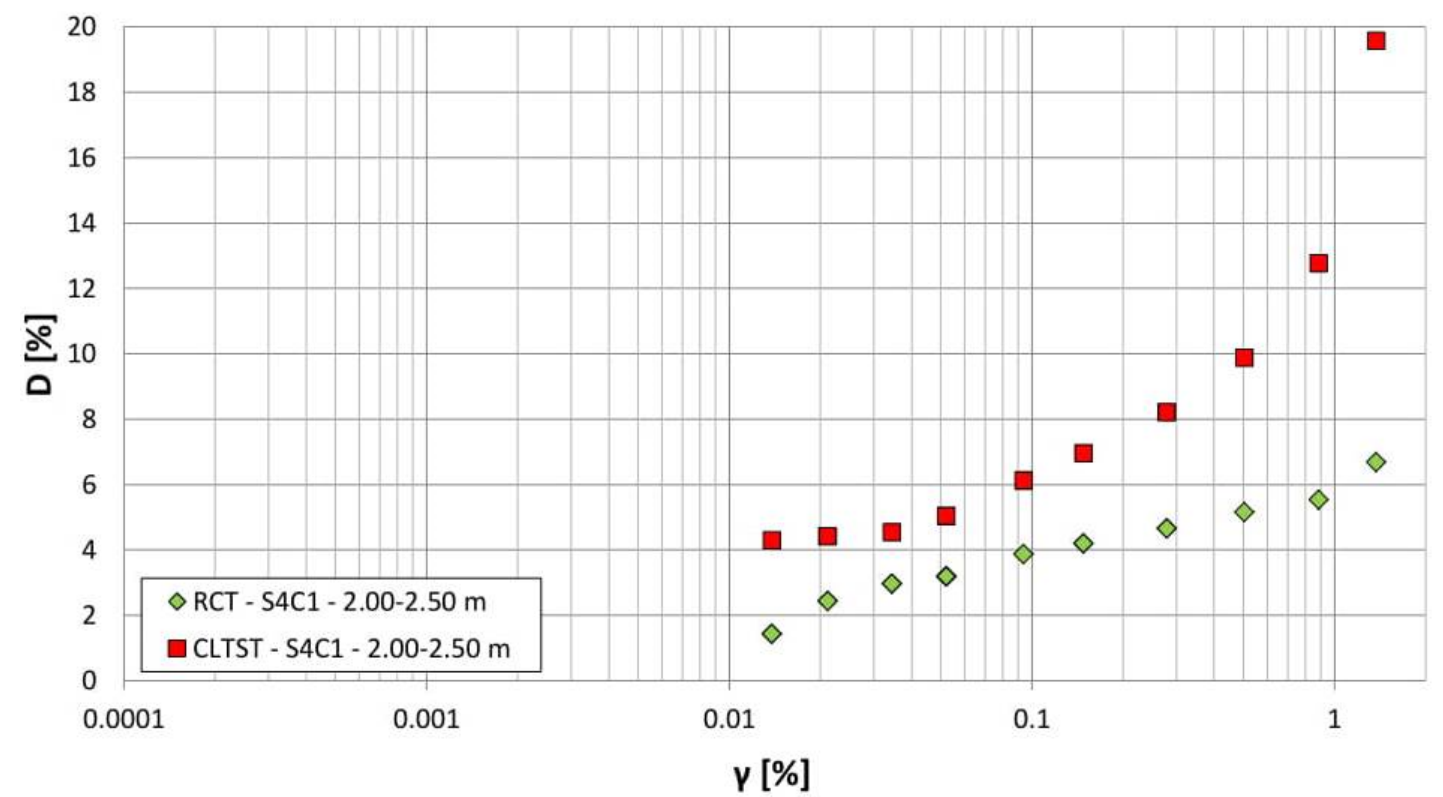

Figure 9. (a) G [MPa] versus $\gamma[\%]$ curves. (b) D [\%] versus $\gamma$ [\%] curves (for the $\mathrm{S} 4 \mathrm{C} 1$ soil sample).

According to these data, it is possible to observe that higher values of $\mathrm{D}$ are obtained by CLTS than RCT.

\subsection{Petrochemical Facilities}

Southeastern Sicily is considered one of the zones of Italy with the highest seismic risk. In the city of Augusta, historically affected by strong earthquakes and high-intensity tsunami events, there are important industrial petrochemical facilities. They are classified with high risk, according to the Seveso III Directive on the control of major-accident hazards involving dangerous substances [30].

One of the main changes introduced by the Seveso III Directive is the recognition of the impact of natural risks on safety management in major accident-generated industrial plants. The accidents generated are called NaTech (Natural Hazard Triggering Technological 
Disasters). The natural events can be rainfall, floods, earthquake, volcanic phenomena, or hurricane [31]. Earthquakes can cause extensive damage to industrial facilities [32].

In this paper, the effects of the soil-foundation-interaction on the seismic response of a cooling tower, located in Augusta, have been studied by 3D-FEM analysis.

The cooling tower under consideration, called C-352, consists of the following components: reinforced concrete (RC) piles, RC plate, RC pedestal, and equipment. Figure 11 shows a scheme of the cooling tower.

(a)

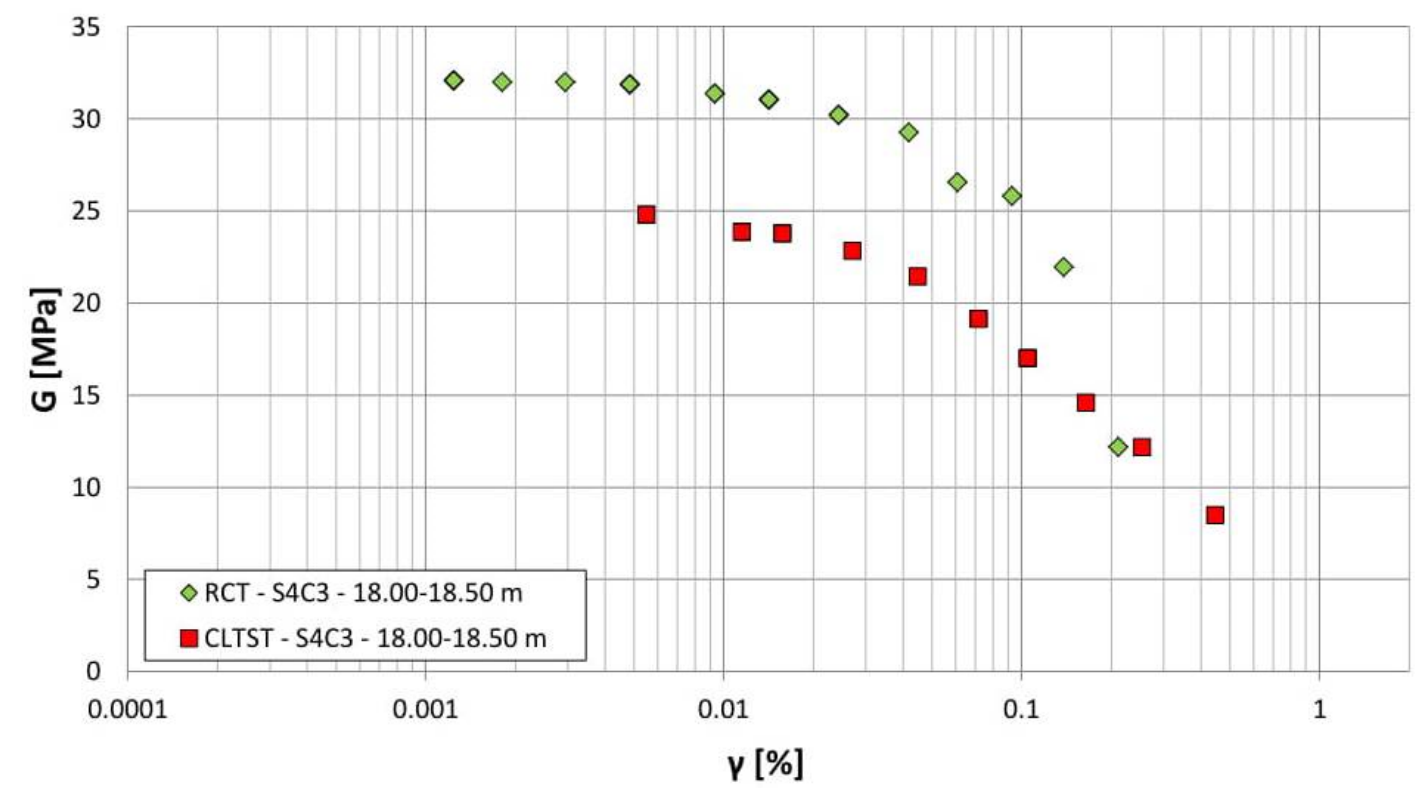

(b)

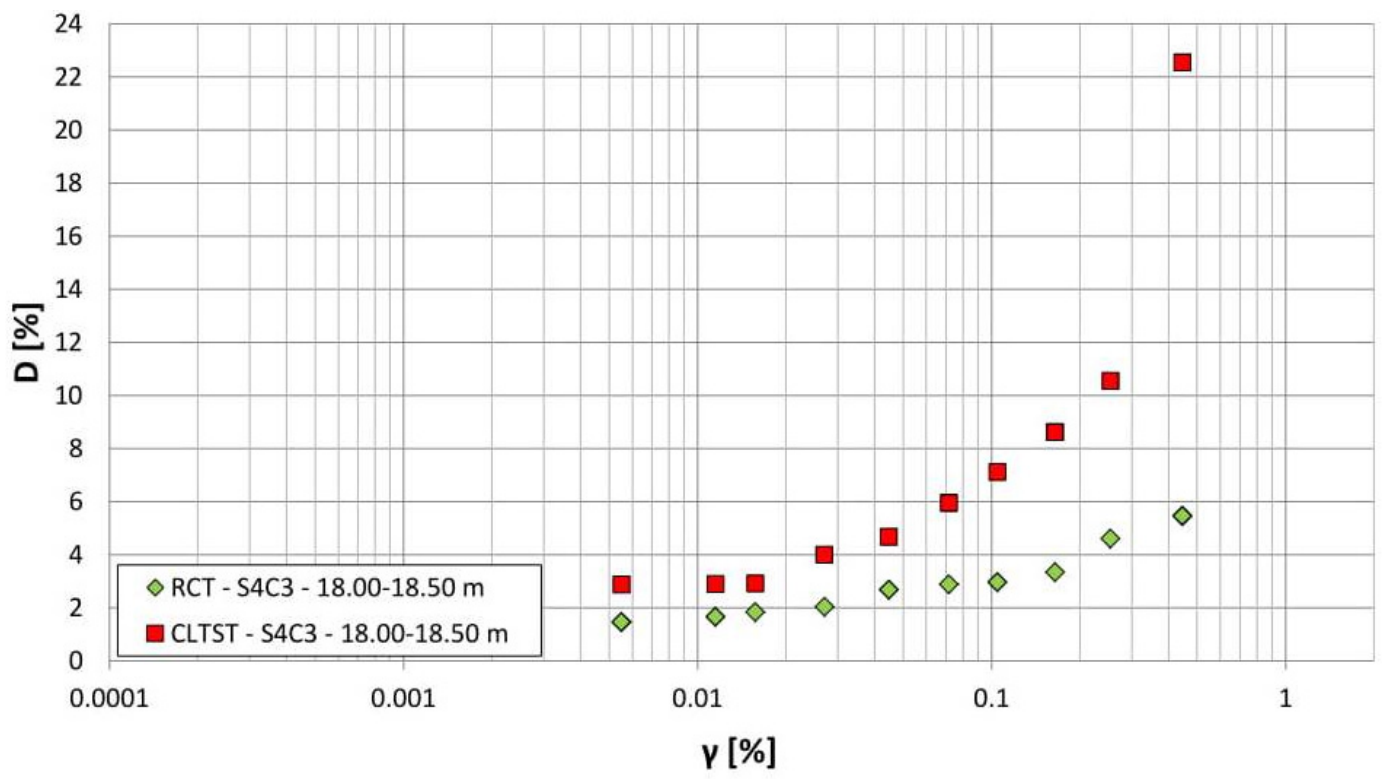

Figure 10. (a) G [MPa] versus $\gamma[\%]$ curves. (b) D [\%] versus $\gamma[\%]$ curves (for S4C3 soil sample).

The position of the equipment is reported in Figure 5. The foundation consists of an octagonal plate (maximum width of $3.50 \mathrm{~m}$ and thickness of $1.00 \mathrm{~m}$ ) on six piles with a diameter of $500 \mathrm{~mm}$ and length of $12.00 \mathrm{~m}$. The plate is set on a layer of lean concrete situated at a depth of $2.00 \mathrm{~m}$. The pedestal (maximum width of $2.10 \mathrm{~m}$ and thickness of $1.20 \mathrm{~m}$ ) has an octagonal section and it is equipped with eight anchor bolts for docking with the equipment. Plan and profile views of the basement are reported in Figures 12 and 13, respectively. 


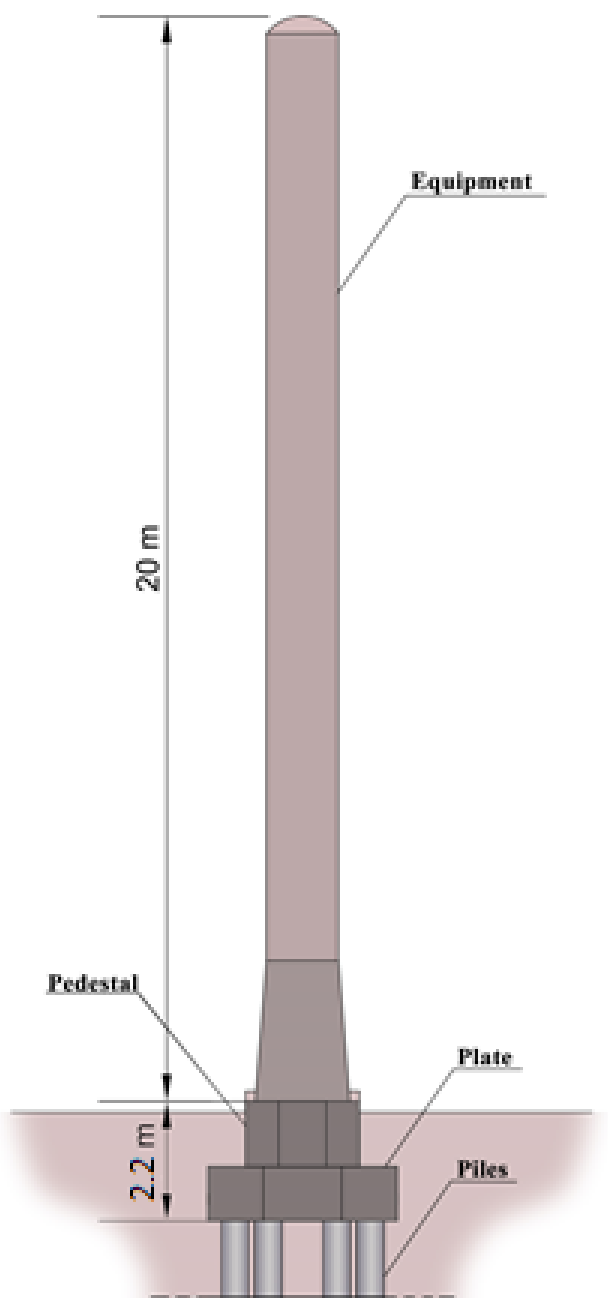

Figure 11. Scheme of the cooling tower.

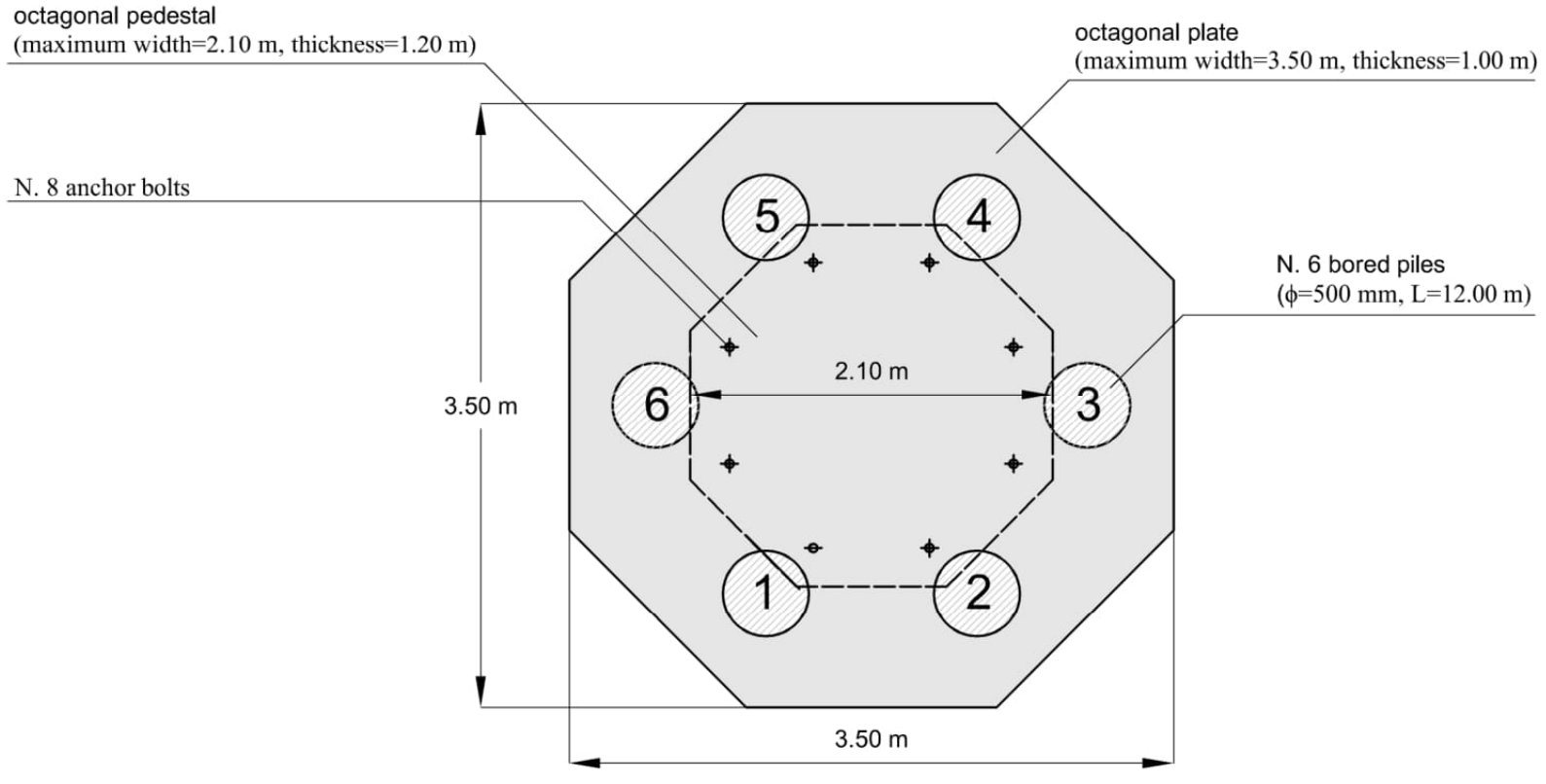

Figure 12. Plan view of the basement. 


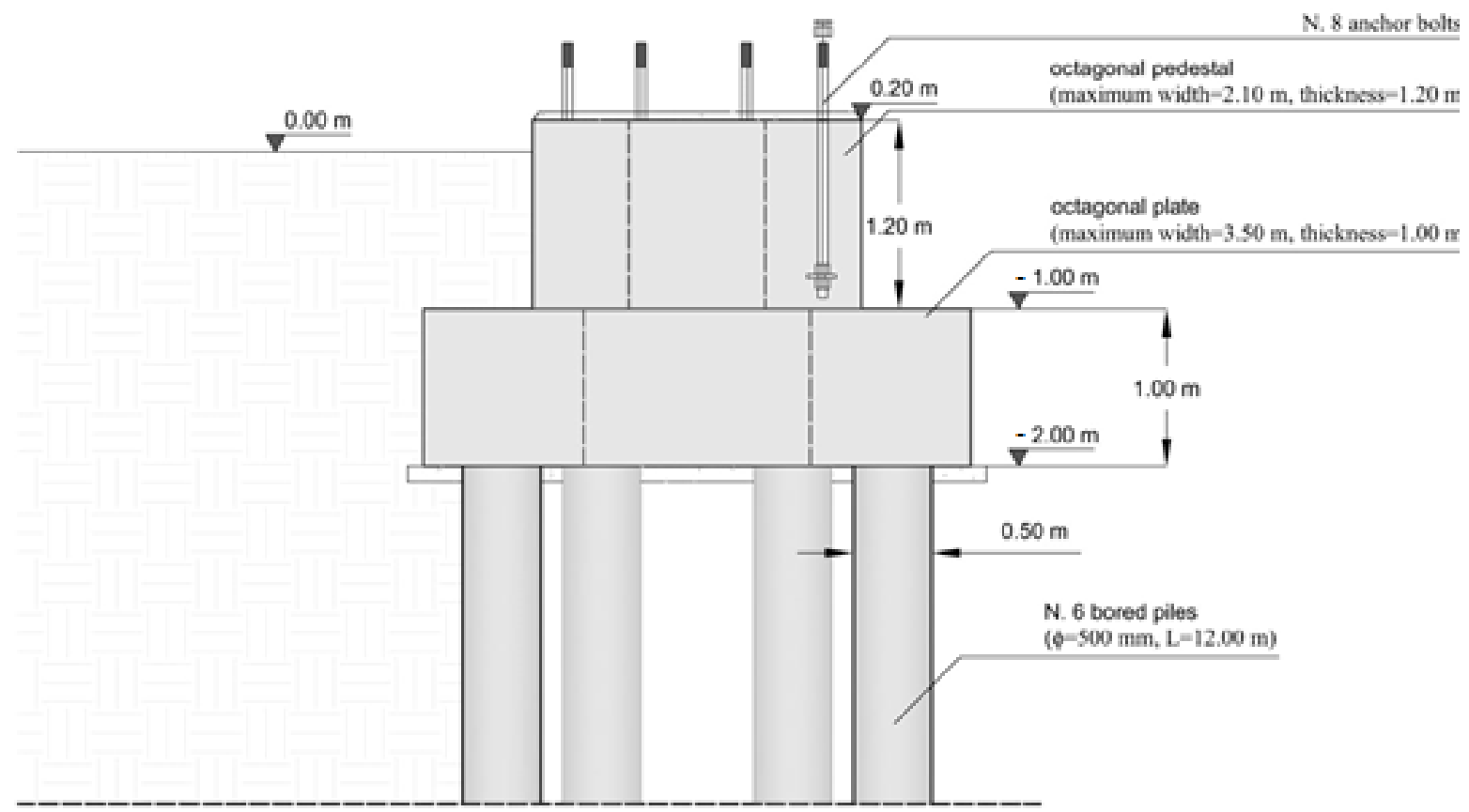

Figure 13. Profile view of the basement.

\section{Model Geometry and Boundary Conditions of Soil}

From in situ characterization (boreholes S1, S2, S3, and S4), it has been possible to define the following soil stratigraphy: Backfill (from 0.00 to $2.50 \mathrm{~m}$ ), Alluvial Deposits (from 2.50 to $12.00 \mathrm{~m}$ ), Sandy Clay (from 12.00 to $17.00 \mathrm{~m}$ ), and Blue-Grey Clay (from 17.00 to $30.00 \mathrm{~m}$ ). The soil profile is shown in Figure 14 .

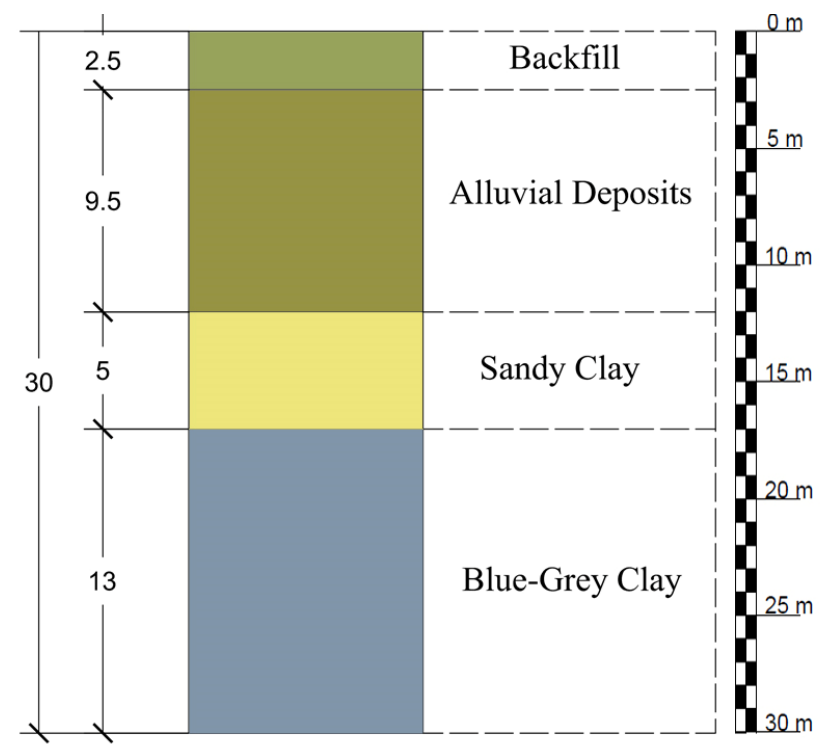

Figure 14. Soil stratigraphy obtained by in situ characterization.

The dynamic response model requires knowledge of bedrock depth. Marzorati et al. [33] and Fiorini et al. [34] carried out a noise measurements campaign in order to obtain the soil resonant frequency in the industrial area. The measures provided the resonant frequency of the soil deposit $\left(\mathrm{f}_{0}\right)$ and gave indications about the average shear wave velocity and the depth of seismic bedrock. The analysis of the noise measurements using the spectral ratios HVSR (Horizontal to Vertical Spectral Ratio) showed the lowest values of $\mathrm{f}_{0}(0.69-1.37 \mathrm{~Hz})$ along the coastal area under consideration (Figure 5). Moreover, the 
results indicated that the most important geotechnical unit in terms of soil response is the blue clay with an average shear wave velocity of $600 \mathrm{~m} / \mathrm{s}$. The same value of $V_{S}$ is also reported by Tortorici [35]. Finally, the results allowed us to identify the surface that generates the amplifications at the base of the blue-grey clays, which constitutes the seismic bedrock [33,34]. The thickness of the blue-grey clay is equal to $73 \mathrm{~m}$ in the studied area [36]. The soil model is shown in Table 3, where $\mathrm{V}_{\mathrm{S}}$ values are obtained from D-H tests and from previous considerations. The values of the unit weight have been provided by the laboratory tests. Finally, the water head has been imposed at a depth of $11 \mathrm{~m}$.

Table 3. Soil Model.

\begin{tabular}{cccccc}
\hline Layers & From $[\mathbf{m}]$ & To $[\mathbf{m}]$ & Thickness $[\mathbf{m}]$ & $\mathbf{V}_{\mathbf{S}}[\mathbf{m} / \mathbf{s}]$ & $\gamma\left[\mathbf{k N} / \mathbf{m}^{\mathbf{3}}\right]$ \\
\hline Backfill & 0 & 2.5 & 2.5 & 202 & 17.9 \\
Alluvial Deposits & 2.5 & 12 & 9.5 & 222 & 17.9 \\
Sandy Clay & 12 & 17 & 5 & 639 & 18.4 \\
Blue-Grey Clay & 17 & 90 & 73 & 600 & 18.7 \\
\hline
\end{tabular}

The fundamental natural frequency of the soil deposit can be calculated according to the following formula.

$$
\mathrm{f}_{0}=\frac{\mathrm{V}_{\mathrm{S}}}{4 \mathrm{H}}
$$

where $V_{S}$ is the shear wave velocity in the soil deposit of thickness $H$. The fundamental natural frequency of the soil deposit is equal to $1.37 \mathrm{~Hz}$.

The dynamic input has been applied along the $\mathrm{x}$-direction by imposing a given displacement at the bottom boundary. In order to minimize boundary effects as much as possible, the length of the model L (along the x-direction) has been chosen to equal $180 \mathrm{~m}$. Instead, the boundary efreects are minimal along the y-direction. Therefore, the width of the model $\mathrm{W}$ has been chosen to equal nine times the equipment's footprint, i.e., $31.5 \mathrm{~m}$.

The basic soil elements of the 3D finite element mesh are the 10-node tetrahedral elements. The average element size (AES) respects the following equation [37].

$$
\mathrm{AES} \leq \frac{\mathrm{V}_{\mathrm{s}, \min }}{6 \div 8 \mathrm{f}_{\max }}
$$

where $V_{S, \min }$ is the lowest wave velocity and $f_{\max }$ is the maximum frequency component of the input wave. The number of elements is 308,703 .

The finite element mesh is shown in Figure 15.

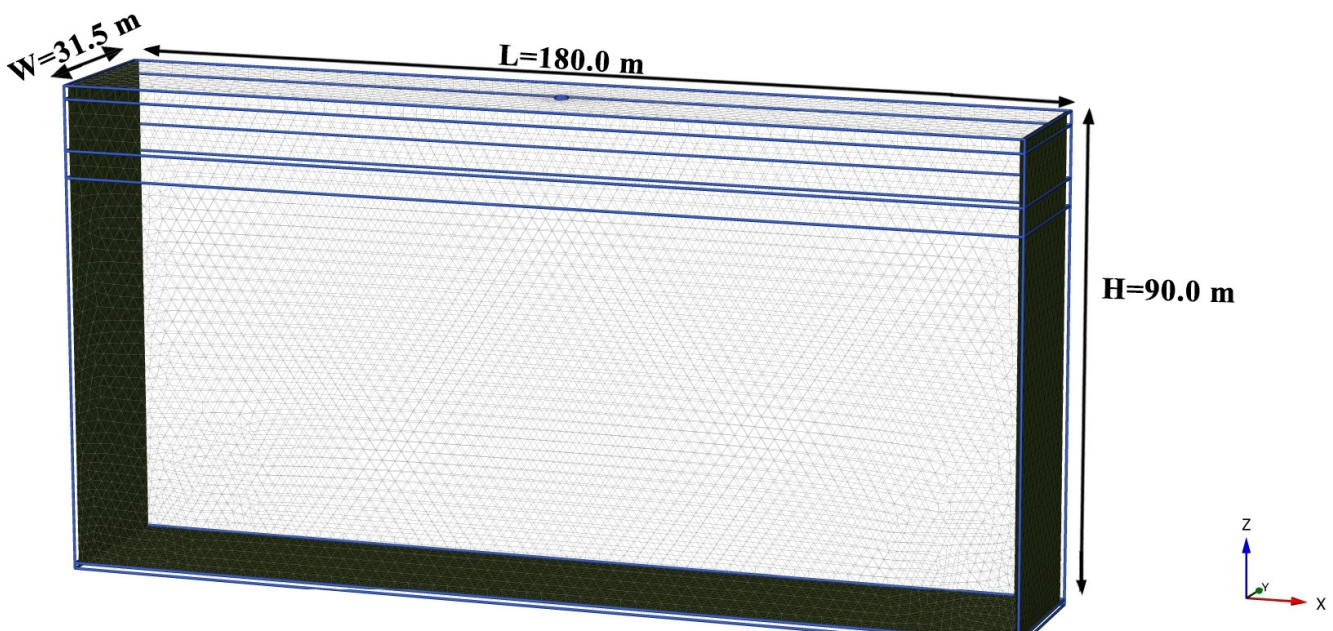

Figure 15. Finite element mesh. 
With regard to the boundary conditions, to generate the initial stresses due to gravity loading, default fixities have been applied, corresponding to normally fixed vertical boundaries and a fully fixed base. For the dynamic phase, the free-field and compliant base boundary conditions have been considered (Figure 16).

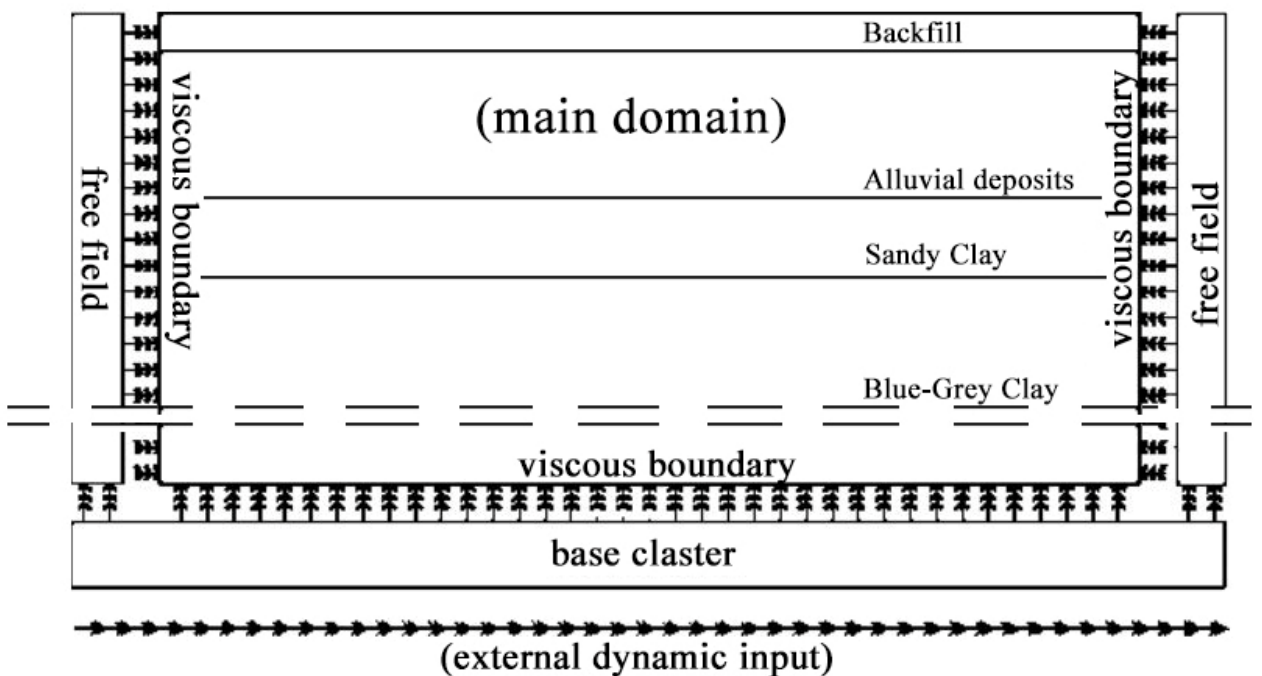

Figure 16. Free field boundary condition with compliant base (After References [38,39], modified).

The free field condition simulates the propagation of waves into the far field with a minimum reflection at the boundary. The domain is reduced to the area of interest and the free field motion is applied to the boundaries employing free-field elements. The motion is transferred from the free field elements to the main domain by applying equivalent normal and shear forces. Two dashpots are added in the normal and shear direction at each node of the model boundary (Figure 17) [38,39].

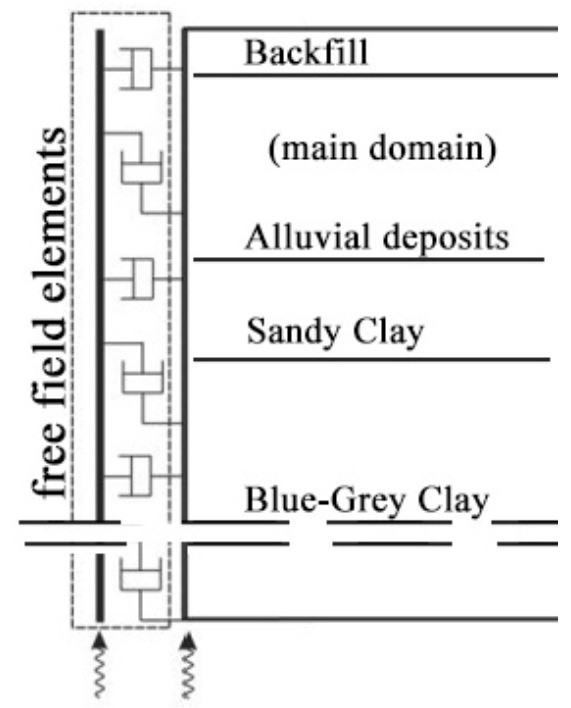

Figure 17. Free field elements (After References [38,39], modified).

The compliant base boundary [40] simulates the continuation of waves into the deep soil with a minimum reflection at the bottom boundary. Free field elements can be attached to the bottom of the main domain and the input signal is transferred to the main domain by applying equivalent normal and shear forces [38,39].

Model geometry and boundary conditions are shown in Figure 18. 


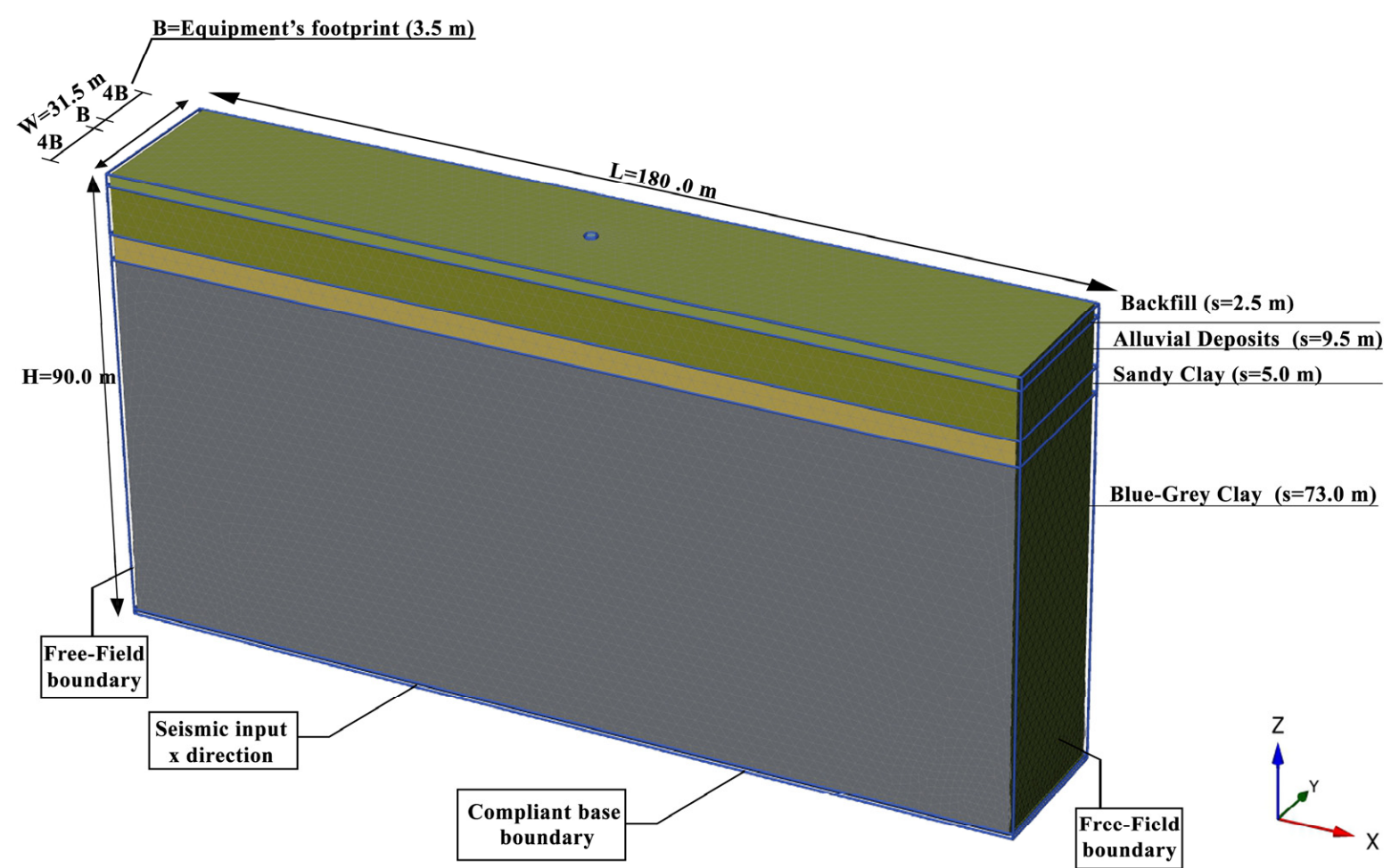

Figure 18. Model geometry and boundary conditions.

\section{Full-Coupled FEM Model}

Dynamic response of a structure deviates from the free field (FF) site response analysis because of a kinematic and inertial interaction [11,41]. The dynamic response of a fullycoupled soil-structure system has been performed by means of PLAXIS 3D software. Two different vertical alignments have been analyzed: along the structure (SSI) and far from the structure (FF), as shown in Figure 19.

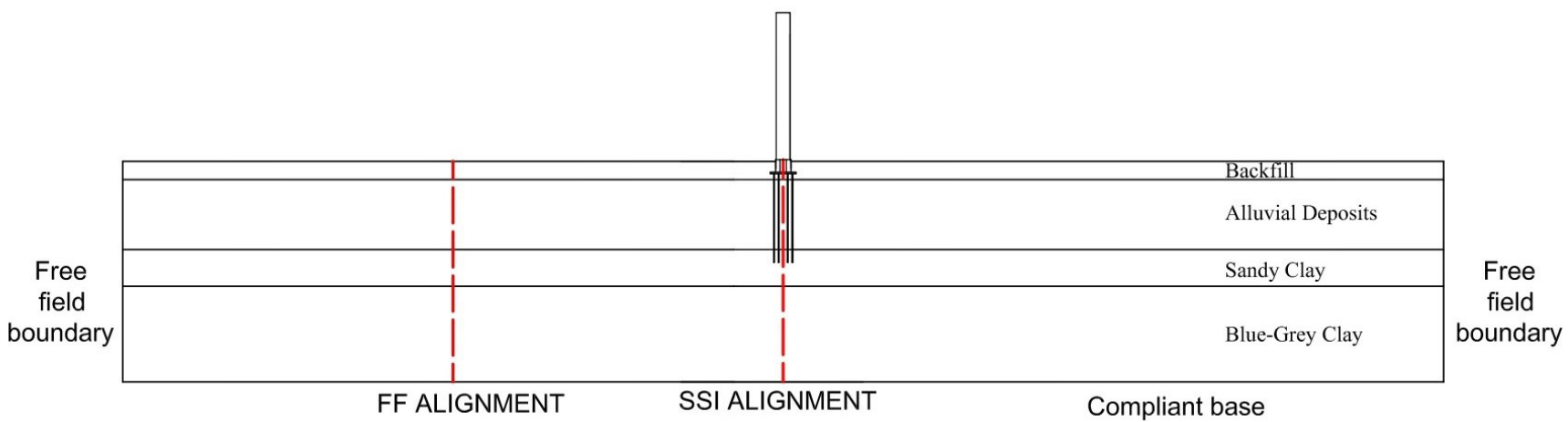

Figure 19. Vertical alignments: along the structure (SSI) and far from the structure (FF).

\subsection{Mohr-Coulomb Model}

The Mohr-Coulomb model has been used for both static and dynamic calculations. The linear elastic perfectly-plastic model requires five parameters as input: Young's modulus $(E)$ and Poisson's ratio $(v)$ for soil elasticity, friction angle $\left(\varphi^{\prime}\right)$ and cohesion $\left(c^{\prime}\right)$ for soil plasticity, and the dilatancy angle $(\psi)$. The stiffness has been defined based on wave 
velocity obtained from the geophysical tests. The following relationships have been used to determine the Young's modulus (E) and Poisson's ratio ( $v)$ from the wave velocities.

$$
\begin{gathered}
v=\frac{\left\lfloor\frac{1}{2}\left(\frac{V_{P}}{V_{S}}\right)^{2}-1\right\rfloor}{\left\lfloor\left(\frac{V_{P}}{V_{S}}\right)^{2}-1\right\rfloor} \\
G=\rho V_{S}^{2} \\
E=2 G(1+v)
\end{gathered}
$$

The friction angle $\left(\varphi^{\prime}\right)$ and cohesion $\left(c^{\prime}\right)$ have been derived directly from direct shear tests. The material properties are reported in Table 4.

Table 4. Material properties.

\begin{tabular}{ccccccccc}
\hline Layers & $\gamma\left[\mathbf{k N} / \mathbf{m}^{\mathbf{3}}\right]$ & $\mathbf{E}\left[\mathbf{k N} / \mathbf{m}^{\mathbf{2}}\right]$ & $\boldsymbol{v}[[-]$ & $\boldsymbol{\varphi}^{\prime}\left[{ }^{\circ}\right]$ & $\mathbf{c}^{\prime}\left[\mathbf{k N} / \mathbf{m}^{\mathbf{2}}\right]$ & $\left.\Psi^{\circ}\right]^{\circ}$ & $\mathbf{V}_{\mathbf{p}}[\mathbf{m} / \mathbf{s}]$ & $\mathbf{V}_{\mathbf{p}} / \mathbf{V}_{\mathbf{s}}$ \\
\hline Backfill & 17.9 & 220,099 & 0.478 & 21 & 24 & 0 & 986 & 4.88 \\
Alluvial Deposits & 17.9 & 268,089 & 0.490 & 21 & 24 & 0 & 1634 & 7.36 \\
Sandy Clay & 18.4 & $2,227,231$ & 0.454 & 24 & 58 & 0 & 2203 & 3.45 \\
Blue-Grey Clay & 18.7 & $1,990,245$ & 0.450 & 25 & 44 & 0 & 1992 & 3.32 \\
\hline
\end{tabular}

Furthermore, in order to simulate the soil's damping characteristics in cyclic loading, Rayleigh damping has been defined. The damping ratio $\xi$ has been taken to equal 10\% [42]. The values of Rayleigh coefficients $\alpha$ and $\beta$ are 2.04552 and 0.00434 , respectively.

\subsection{Structural Elements and Loads}

In the finite element analysis, structural elements have been simulated by means of the elastic constitutive model.

The piles have been modelled as embedded beams. The embedded beam approach was introduced by Sadek and Sharhour [43]. In PLAXIS 3D, the embedded beam element is modelled as a three-node line element (beam element) that can cross a 10-node tetrahedral element, representing the soil in any place with any arbitrary orientation [44]. Due to the presence of the beam element, three extra nodes are introduced inside the 10-node tetrahedral element [45] (Figure 20).

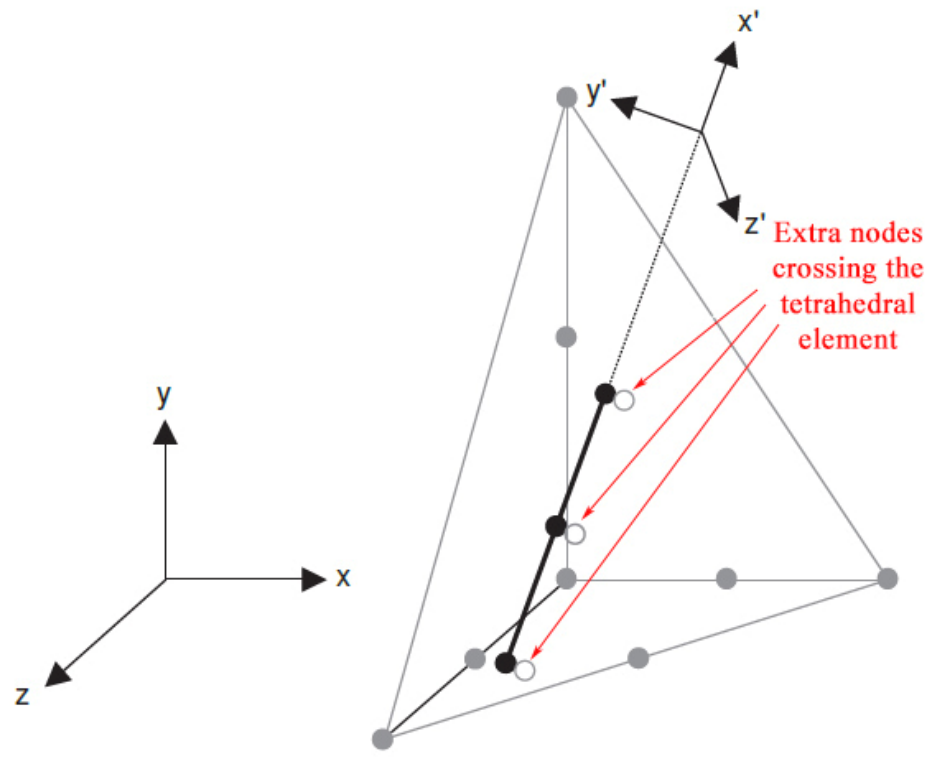

Figure 20. Embedded beam element (After Brinkgreve et al. [45], modified). 
An elastoplastic model is used to describe the behavior of the interface. The interaction could involve a skin resistance as well as a foot resistance. For the skin and the base resistance, a failure criterion is used to distinguish between elastic and plastic interface behavior. For the interface, to remain elastic, the shear force $\left(t_{s}\right)$ at a particular point is given by:

$$
\left|\mathrm{t}_{\mathrm{s}}\right|<\mathrm{T}_{\max }
$$

For the plastic behavior:

$$
\left|\mathrm{t}_{\mathrm{s}}\right|<\mathrm{T}_{\max }
$$

where $T_{\max }$ is the equivalent local skin resistance at that point.

The total pile bearing capacity, $\mathrm{N}_{\text {pile, }}$, is given by:

$$
\mathrm{N}_{\text {pile }}=\mathrm{F}_{\max }+\mathrm{F}_{\text {skin }}
$$

where $F_{\max }$ is the base resistance and $F_{\text {skin }}$ is the axial skin resistance $[46,47]$.

The base resistance has been calculated using the following equation.

$$
\mathrm{F}_{\max }=\mathrm{A}_{\mathrm{p}}\left(\mathrm{c}_{\mathrm{u}} \mathrm{N}_{\mathrm{c}}+\sigma_{\mathrm{v} 0, \mathrm{p}}\right)
$$

where $A_{p}=$ base area of pile, $c_{u}=$ undrained cohesion at the base of the pile, $N_{c}=$ bearing capacity factor, assumed to equal 9 , and $\sigma_{\mathrm{v} 0, \mathrm{p}}=$ vertical total stress at the base of the pile.

The skin resistance has been related to the strength of soil in which the pile is located:

$$
\begin{gathered}
\tau_{\mathrm{i}}=\mathrm{c}_{\mathrm{i}}+\sigma_{\mathrm{n}}^{\prime} \tan \varphi_{\mathrm{i}} \\
\mathrm{c}_{\mathrm{i}}=\mathrm{R}_{\text {inter }} \mathrm{c}_{\text {soil }} \\
\tan \varphi_{\mathrm{i}}=\mathrm{R}_{\text {inter }} \tan \varphi_{\text {soil }}
\end{gathered}
$$

where $\tau_{i}$ is the local shear stress resistance of the interface, $\varphi_{i}$ and $c_{i}$ are the friction angle and the cohesion of the interface, $\varphi_{\text {soil }}$ and $c_{\text {soil }}$ are the friction and the cohesion of the correspondent soil layer, $R_{\text {inter }}$ is the strength reduction factor, and $\sigma_{n}^{\prime}=\left(\sigma_{2}^{\prime}+\sigma_{3}^{\prime}\right) / 2$ is the normal stress.

The interaction has been modeled by choosing a suitable value for the strength reduction factor in the interface. $R_{\text {inter }}$ has been assumed to be $2 / 3$.

For elasticity, the properties required are the Young modulus $\mathrm{E}$ and the unit weight of the beam element $\gamma$. Regarding geometric properties, the value of the cross-section area $\mathrm{A}$ and the moments of inertia have been calculated from the diameter of the massive circular pile. The embedded beam diameter determines the size in which plastic soil behavior is excluded.

Material properties of piles are reported in Table 5.

Table 5. Material properties of embedded beams.

\begin{tabular}{cccc}
\hline Parameter & Symbol & Pile Foundation & Unit \\
\hline Young's modulus & $\mathrm{E}$ & $32,587,468$ & $\mathrm{kN} / \mathrm{m}^{2}$ \\
Unit weight & $\gamma$ & 25 & $\mathrm{kN} / \mathrm{m}^{3}$ \\
Beam type & - & Massive circular beam & - \\
Diameter & $\mathrm{D}$ & 0.5 & $\mathrm{~m}$ \\
Axial skin resistance & $\mathrm{T}_{\text {skin }}$ & Layer dependent & $\mathrm{kN} / \mathrm{m}$ \\
Strength reduction factor & $\mathrm{R}_{\text {inter }}$ & 0.67 & - \\
Base resistance & $\mathrm{F}_{\max }$ & 1061 & $\mathrm{kN}$ \\
\hline
\end{tabular}

Finally, the displacement and rotation at the pile head are both coupled with the displacement and rotation of the structural element in which the pile top is located.

The octagonal foundation plate has been modeled as Plate. After meshing, plates are composed of six-node triangular plate elements with six degrees of freedom per node. A 
plate has the following general and stiffness properties: thickness $d$, unit weight $\gamma$, Young's modulus in the first axial direction $\mathrm{E}_{1}$, Young's modulus in the second axial direction $\mathrm{E}_{2}$, in-plane shear modulus $G_{12}$, out-of-plane shear modulus related to shear deformation over the first direction $\mathrm{G}_{13}$, out-of-plane shear modulus related to shear deformation over the second direction $\mathrm{G}_{23}$ and Poisson's ratio $v_{12}$. The material behavior has been considered as orthotropic. Therefore:

$$
\begin{gathered}
E_{1}=E_{2} \\
G_{12}=G_{13}=G_{23}=\frac{E}{2\left(1+v_{12}\right)}
\end{gathered}
$$

Table 6 shows the material properties of the plate.

Table 6. Material properties of the plate.

\begin{tabular}{cccc}
\hline Parameter & Symbol & Plate Foundation & Unit \\
\hline Thickness & $\mathrm{d}$ & 1.2 & $\mathrm{~m}$ \\
Unit weight & $\gamma$ & 25 & $\mathrm{kN} / \mathrm{m}^{3}$ \\
Type of behavior & - & Elastic, orthotropic & - \\
Young's Modulus & $\mathrm{E}_{1}=\mathrm{E}_{2}$ & $32,587,468$ & $\mathrm{kN} / \mathrm{m}^{2}$ \\
Poisson's ratio & $v_{12}$ & 0.2 & - \\
Shear Modulus & $\mathrm{G}_{12}=\mathrm{G}_{13}=\mathrm{G}_{23}$ & $13,578,111$ & $\mathrm{kN} / \mathrm{m}^{2}$ \\
\hline
\end{tabular}

Finally, the octagonal pedestal has been modelled with an elastic constitutive model $\left(\mathrm{E}=32,587,468 \mathrm{kN} / \mathrm{m}^{2}, v=0.2, \gamma=25 \mathrm{kN} / \mathrm{m}^{3}\right)$.

In this study, operating and earthquake loads have been applied to the model. Operating dead load, $\mathrm{D}_{\mathrm{o}}$, is the empty weight of equipment plus the maximum weight of contents (fluid load) during a normal operation [5]. It has been simulated as a cylindrical column with a total weight of $294 \mathrm{kN}$.

With regard to the earthquake loads, the seismic event that occurred in January 1693 has been chosen as a scenario earthquake. It was evaluated assuming the source to be along the Hyblean-Maltese fault and generating the 1693 seismic ground motion scenario [48-50]. The seismogram has been scaled to the value of $0.350 \mathrm{~g}$, which corresponds to a return period of 975 years in the actual Italian seismic code NTC 2018 [51] (Figure 21). The predominant frequency of the 1693 input motion is $3.9 \mathrm{~Hz}$. Furthermore, the response analysis to the earthquake on 13 December 1990 has been obtained using as base excitation as the record at the Sortino E-W component (Figure 22) being the most representative of the earthquake. It has a PGA of $0.1 \mathrm{~g}$ and a predominant frequency of $1.82 \mathrm{~Hz}$. Finally, in order to perform a parametric study with different input motions, the response analysis was also carried out using the recorded accelerogram of the 2012 earthquake at the Mirandola (MRN) station as excitation at the base of the model. On 20 May 2012, an earthquake of magnitude $\mathrm{M}_{\mathrm{W}}=6.1$ struck the Emilia Romagna Region of Italy and a small portion of the Lombardia region caused 27 deaths and considerable damage [52]. The MRN station is located at an epicentral distance of $13 \mathrm{~km}$ and is classified as a C site [42]. Therefore, a deconvolution analysis has been performed to obtain the appropriate input motion at the bedrock $\left(\right.$ PGA $=0.30 \mathrm{~g}, \mathrm{f}_{\mathrm{p}}=1.93 \mathrm{~Hz}$ ) (Figure 23). 


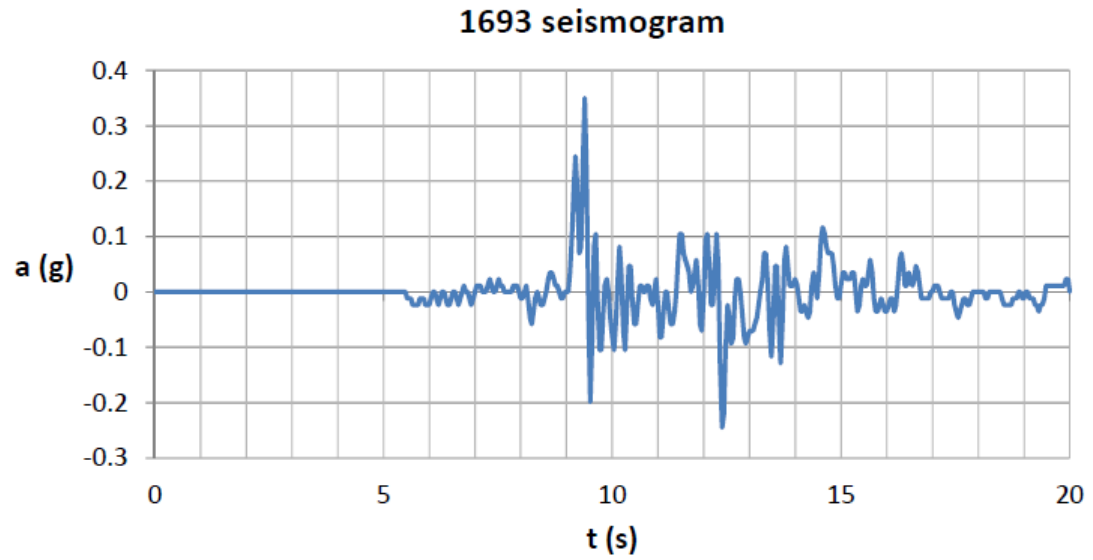

Figure 21. Seismogram of 1693 scaled to the value of $0.350 \mathrm{~g}$ corresponding to a return period of 975 years in the actual Italian seismic code [51].

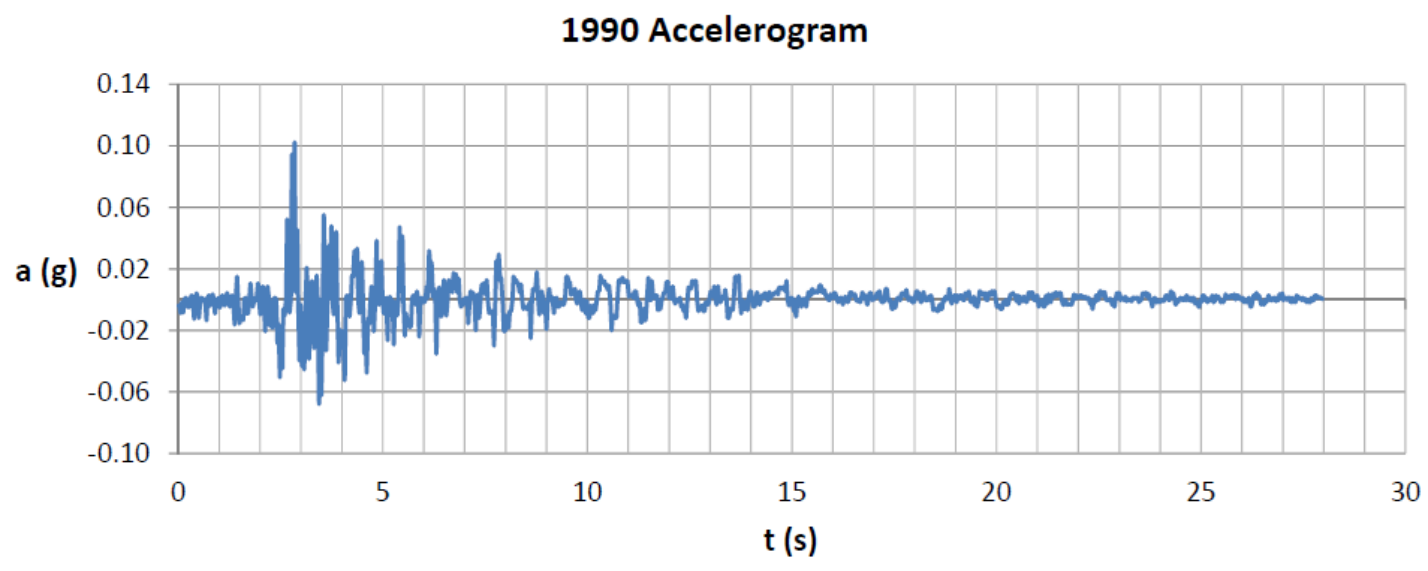

Figure 22. Accelerogram recorded at Sortino during the earthquake on 13 December 1990 [53].

2012 accelerogram

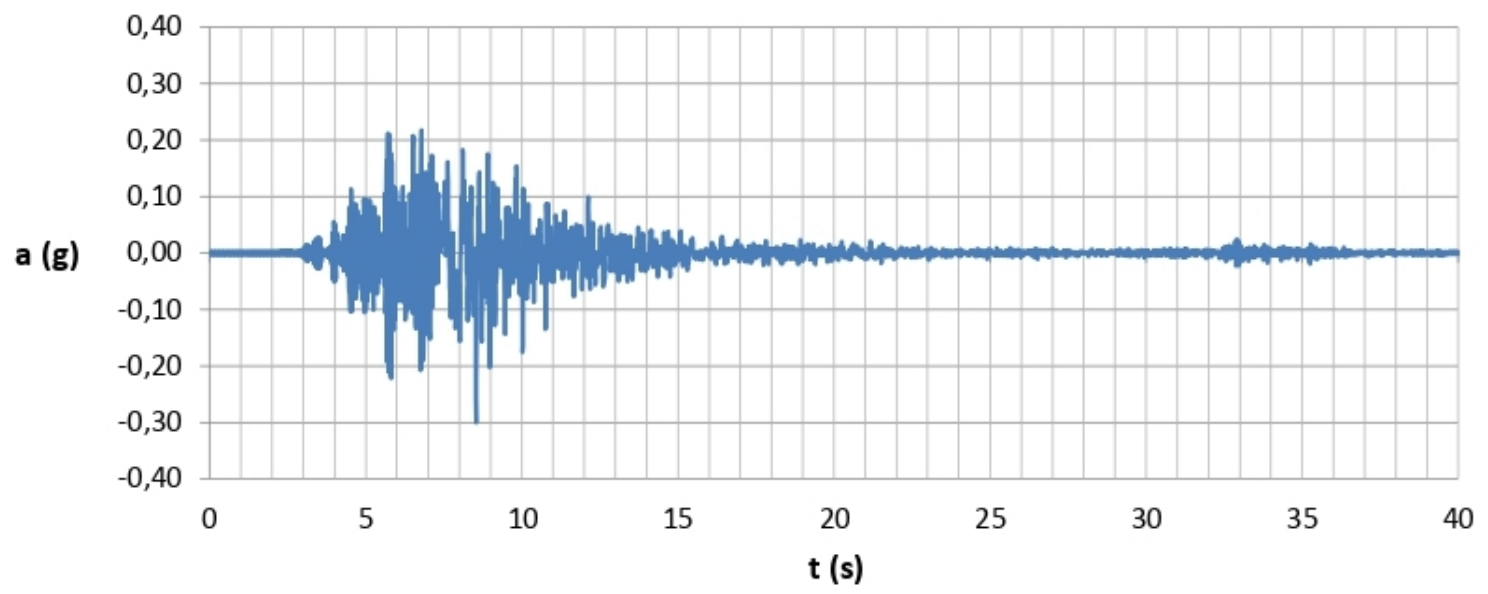

Figure 23. Accelerogram of 2012 earthquake at the bedrock.

The schematic geometric model used to investigate the seismic response of the fullycoupled system is reported in Figure 24. 


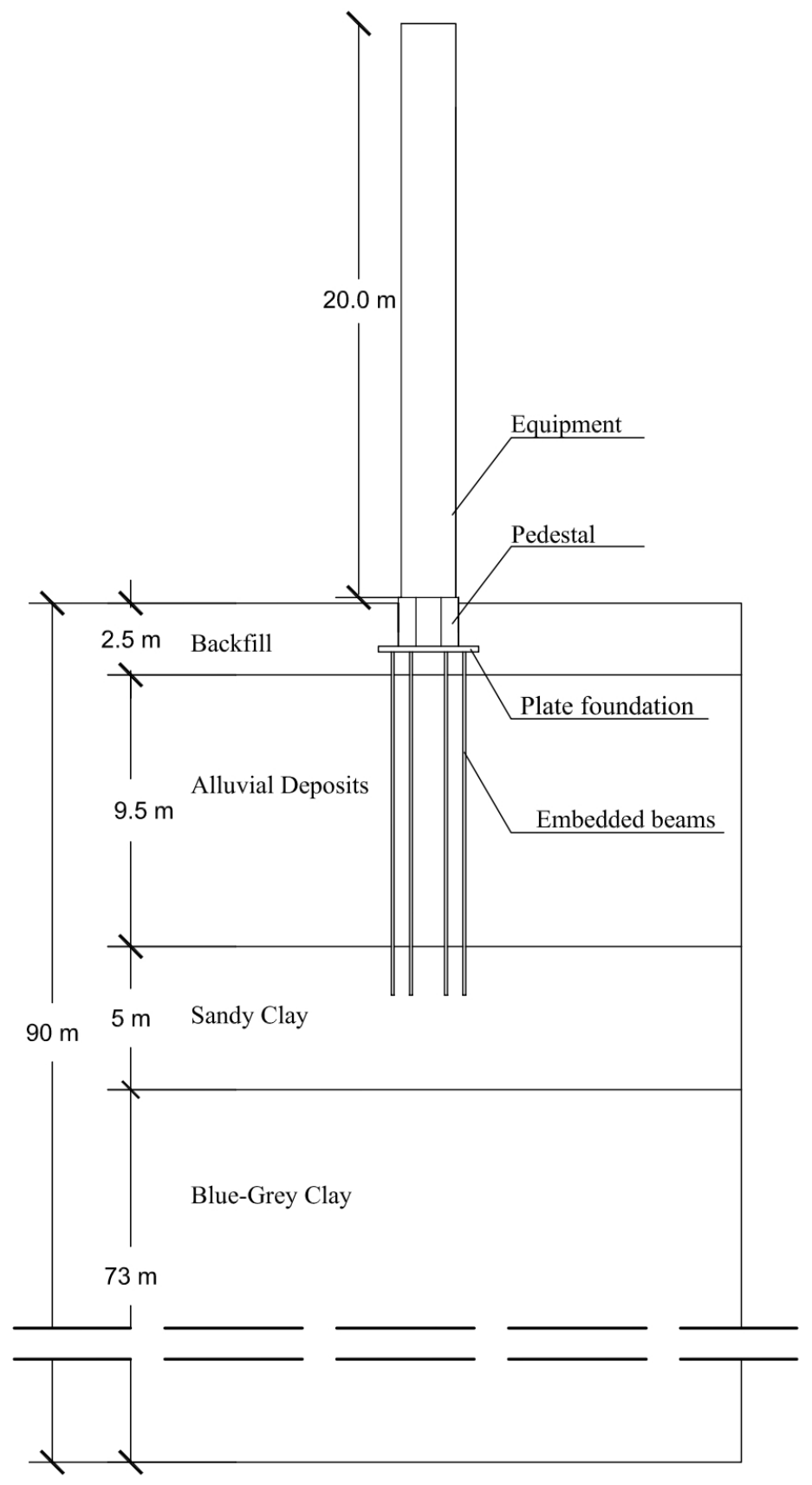

Figure 24. Schematic geometric model.

\subsection{Results}

Regarding the two different alignments reported in Figure 19, the dynamic response has been investigated including its accelerations, response spectra, and amplification functions.

The numerical results from the analyses are shown in Figure 25 describing maximum accelerations with a depth using 1990, 2012, and 1693 seismic inputs. 


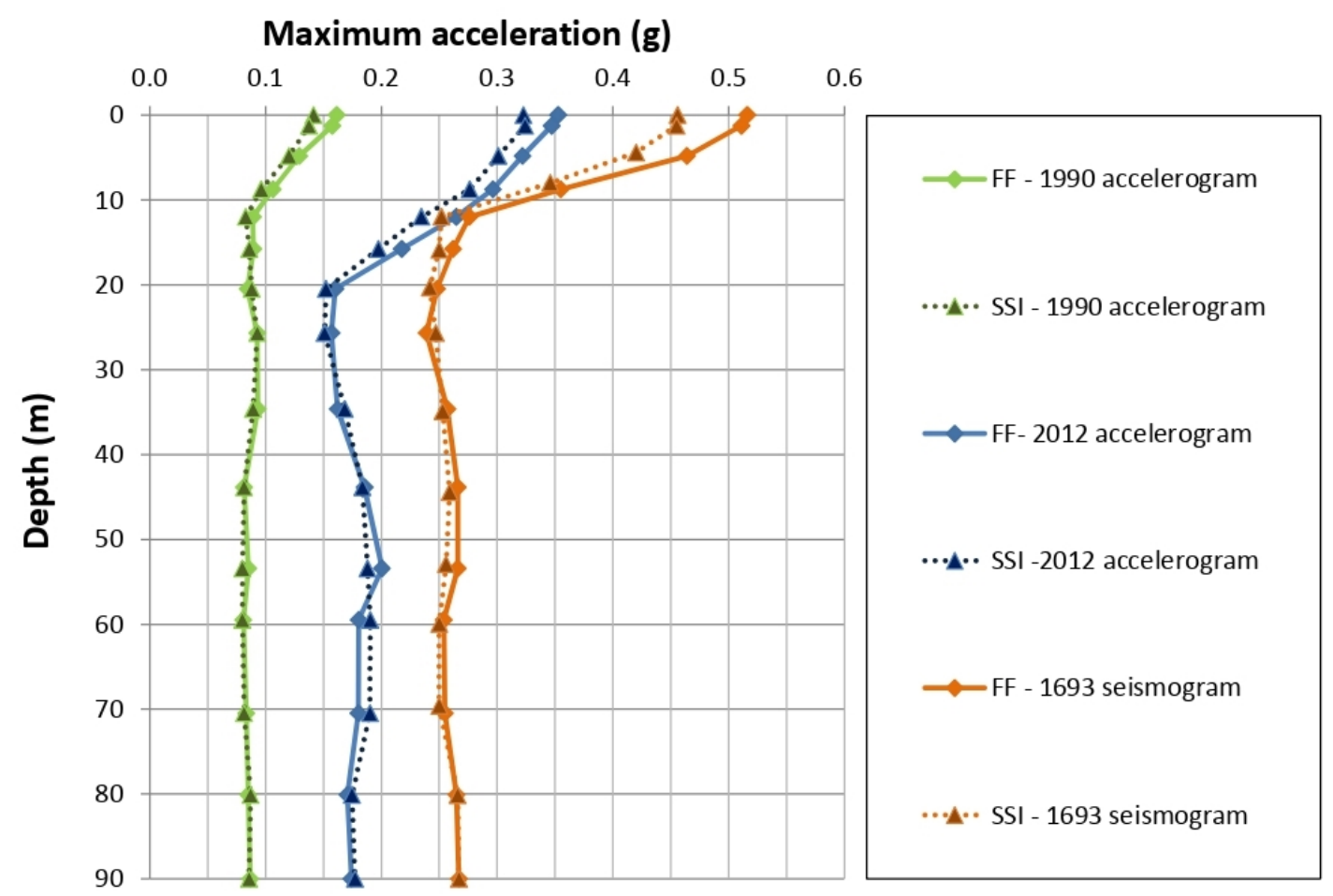

Figure 25. Maximum accelerations along SSI and FF alignments: using the 1990, 2012, and 1693 seismic inputs.

The values of the surface maximum accelerations and soil amplification factors $\mathrm{R}$ for the SSI and FF alignments are reported in Table 7.

Table 7. Values of the surface maximum accelerations and soil amplification factors. FF: SSI:

\begin{tabular}{ccccccc}
\hline & FF, 1990 & SSI, 1990 & FF, 2012 & SSI, 2012 & FF, 1693 & SSI, 1693 \\
\hline PGA $_{\text {input }}$ & $0.10 \mathrm{~g}$ & $0.10 \mathrm{~g}$ & $0.30 \mathrm{~g}$ & $0.30 \mathrm{~g}$ & $0.35 \mathrm{~g}$ & $0.35 \mathrm{~g}$ \\
PGA $_{\text {output }}$ & $0.16 \mathrm{~g}$ & $0.14 \mathrm{~g}$ & $0.35 \mathrm{~g}$ & $0.32 \mathrm{~g}$ & $0.52 \mathrm{~g}$ & $0.46 \mathrm{~g}$ \\
\hline $\mathrm{R}=\mathrm{PGA}_{\text {output }} / \mathrm{PGA}_{\text {input }}$ & 1.60 & 1.40 & 1.17 & $1.07 \mathrm{~g}$ & 1.49 & 1.31 \\
\hline
\end{tabular}

The results show that the 2012 and 1693 input motions are subjected to an evident amplification in the last $20 \mathrm{~m}$ and the 1990 accelerogram is subjected to an amplification in the last $10 \mathrm{~m}$. The comparison between the alignment along the structure (SSI) and the alignment far from the structure (FF) shows that the presence of the structure generates a lower amplification. The soil amplification factors for FF alignment are greater than that achieved for SSI alignment.

In this case, the soil-structure interaction has beneficial effects. However, it is important to investigate and understand the SSI effects because the interaction can sometimes be detrimental. Furthermore, in both alignments, the soil amplification factors obtained using the 1990 and 1693 input motions are greater than the amplification value provided by Italian technical code [51], equal to 1.21 for soil type C. The smallest values of $\mathrm{R}$ were found for the 2012 accelerogram.

In Figure 26, the results are presented in term of response spectra at the surface, obtained by setting a structural damping of 5\% and using the 1693 seismogram as inputs and the 1990 and 2012 accelerograms. For comparison, the elastic response spectrum provided by the Italian seismic code [51] is shown. 
(a)
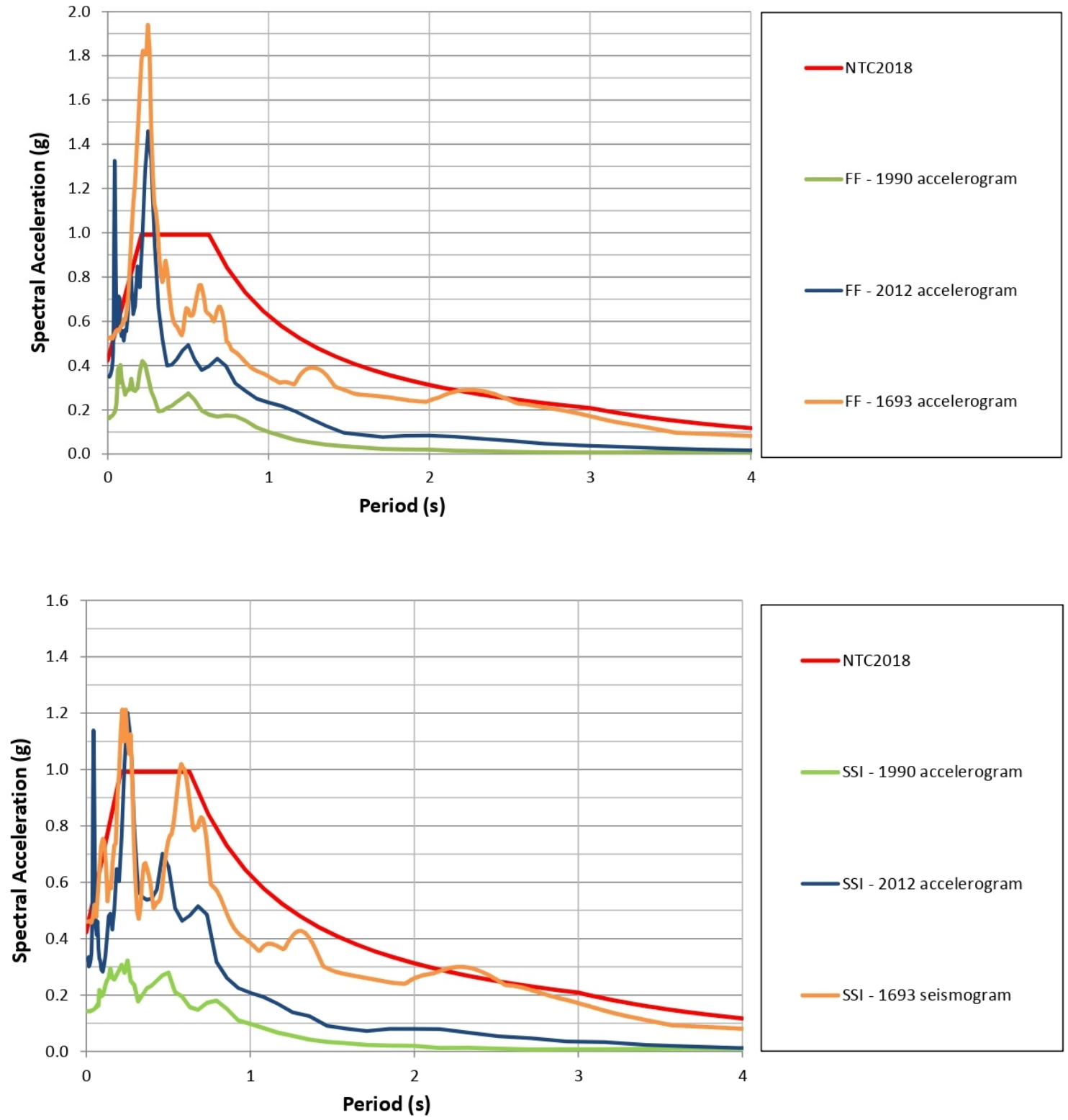

Figure 26. Comparison between the elastic response spectra obtained by numerical analyses and the same provided by NTC 2018 [51]: (a) FF alignment. (b) SSI alignment.

Considering the results obtained using the 1693 seismogram, for the free-field condition (Figure 26a), the maximum spectral acceleration $\mathrm{S}_{\mathrm{e}, \max }=1.94 \mathrm{~g}$ at $\mathrm{T}=0.25 \mathrm{~s}$ is obtained, while, for the SSI alignment (Figure 26b), the maximum spectral acceleration $\mathrm{S}_{\mathrm{e}, \max }=1.21 \mathrm{~g}$ at $\mathrm{T}=0.24 \mathrm{~s}$ is found. A second less important period $\mathrm{T}=0.58 \mathrm{~s}$ can be observed in the SSI condition.

The results obtained using the 2012 accelerogram show that the maximum spectral acceleration $S_{e, \max }=1.46 \mathrm{~g}$ at $\mathrm{T}=0.25 \mathrm{~s}$ is obtained for the free-field condition (Figure 26a), while, for the SSI alignment (Figure 26b), the maximum spectral acceleration $S_{e, \max }=1.20 \mathrm{~g}$ at $\mathrm{T}=0.25 \mathrm{~s}$ is found. A second less important period $\mathrm{T}=0.05 \mathrm{~s}$ can be observed in $\mathrm{FF}$ and SSI conditions.

In both cases, the maximum spectral acceleration is lower, considering full-coupled analysis. Furthermore, for a period T greater than $0.3 \mathrm{~s}$, the elastic response spectrum provided by NTC 2018 [51] is more conservative than those obtained from FEM analysis. 
Finally, considering the 1990 accelerogram, for the free-field condition (Figure 26a), the maximum spectral acceleration $S_{e, \max }=0.41 \mathrm{~g}$ at $\mathrm{T}=0.23$ is obtained, while, for the SSI alignment, the maximum spectral acceleration $\mathrm{S}_{\mathrm{e}, \max }=0.32 \mathrm{~g}$ at $\mathrm{T}=0.25$ is found.

Figure 27 shows the amplification functions $\mathrm{A}(\mathrm{f})$ evaluated as the ratio between the Fourier spectrum at the surface level and the Fourier spectrum at the bedrock level instead of the SSI.

(a)

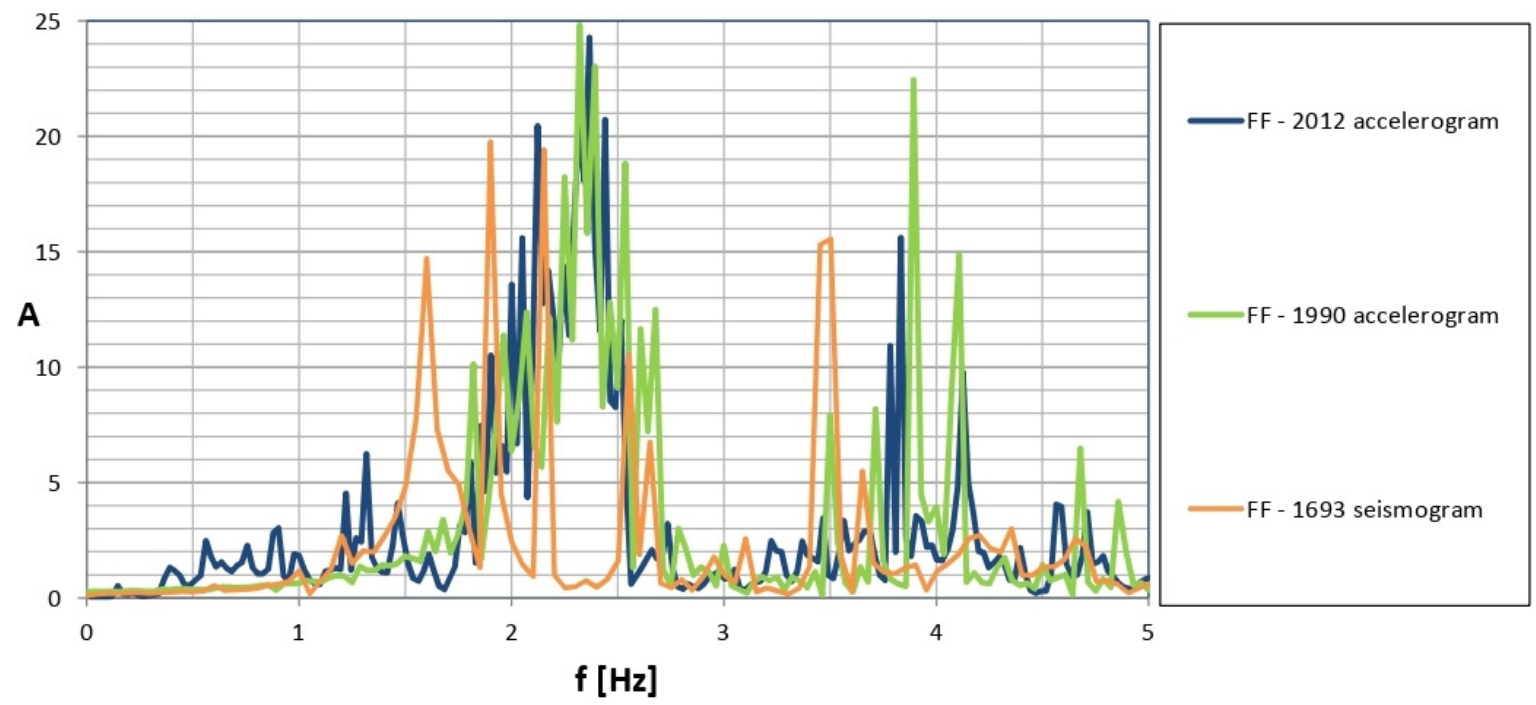

(b)

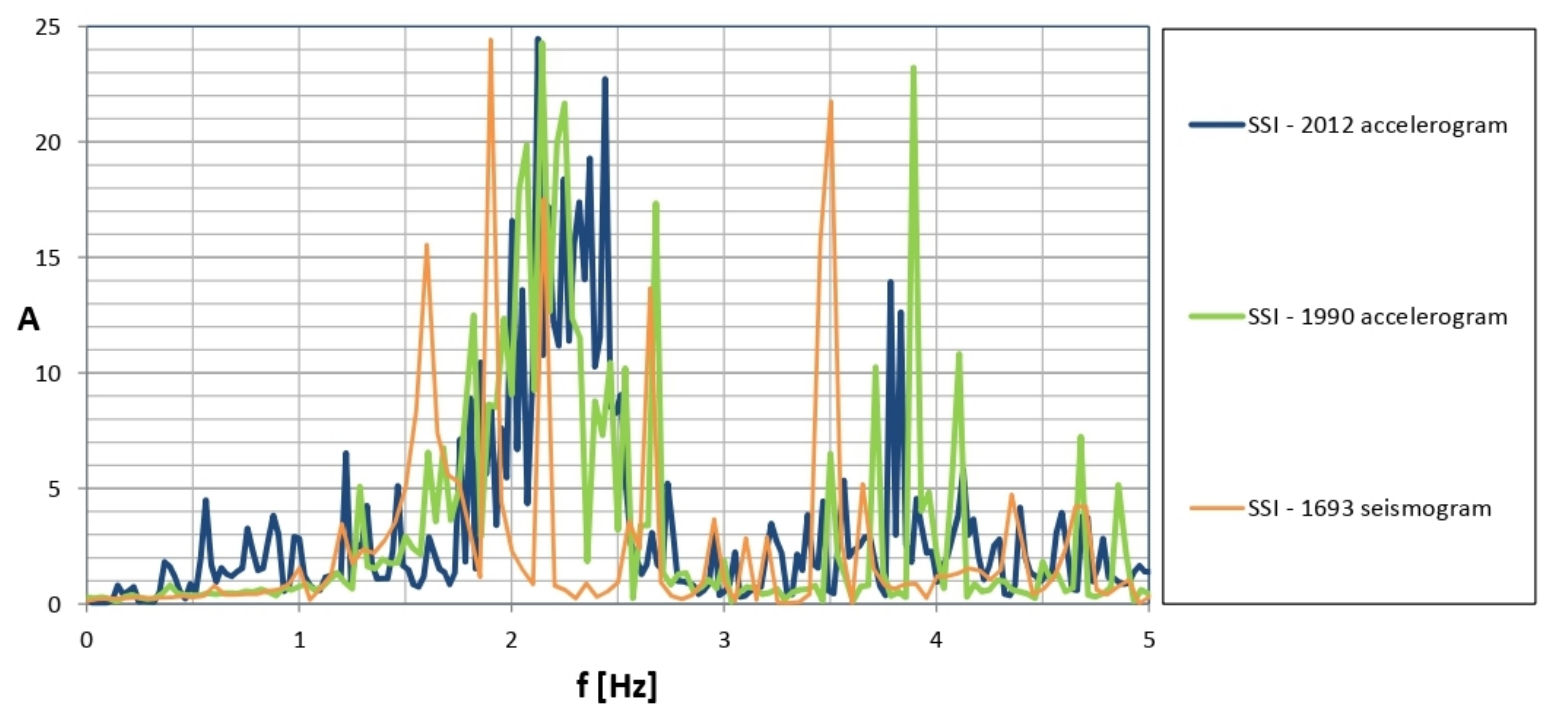

Figure 27. Amplification functions for each seismic input: (a) FF alignment, and (b) SSI alignments.

It is possible to observe that, between the amplification functions achieved for SSI and FF alignments, there are no substantial differences. Moreover, Figure 27 shows that the main resulting frequencies for SSI and FF conditions are equal to: $\mathrm{f}_{\mathrm{FF}}(\mathrm{I})=\mathrm{f}_{\mathrm{SSI}}(\mathrm{I})=2.1 \mathrm{~Hz}$ and $\mathrm{f}_{\mathrm{FF}}(\mathrm{II})=\mathrm{f}_{\mathrm{SSI}}(\mathrm{II})=3.7 \mathrm{~Hz}$. Therefore, $\mathrm{A}(\mathrm{f})$ peaks move toward greater frequencies in comparison with the fundamental natural frequency of the soil $\left(\mathrm{f}_{0}=1.37 \mathrm{~Hz}\right)$. These results are due to the higher predominant frequencies of the input motions.

The fundamental period of the fixed-base structure $\left(\mathrm{T}_{\mathrm{STRU}, \mathrm{FB}}\right)$ can computed by the following expression [5]: 


$$
\mathrm{T}_{\mathrm{STRU}, \mathrm{FB}}=\frac{7.78}{10^{6}}\left(\frac{\mathrm{H}}{\mathrm{D}}\right)^{2} \sqrt{\frac{12 \mathrm{WD}}{\mathrm{t}}}
$$

where $\mathrm{T}=$ period $(\mathrm{s}), \mathrm{W}=$ weight $(\mathrm{lb} / \mathrm{ft}), \mathrm{H}=$ height $(\mathrm{ft}), \mathrm{D}=$ diameter $(\mathrm{ft})$, and $\mathrm{t}=$ shell thickness (inch). Equation (15) is valid for the uniform cylindrical column (Figure 28).

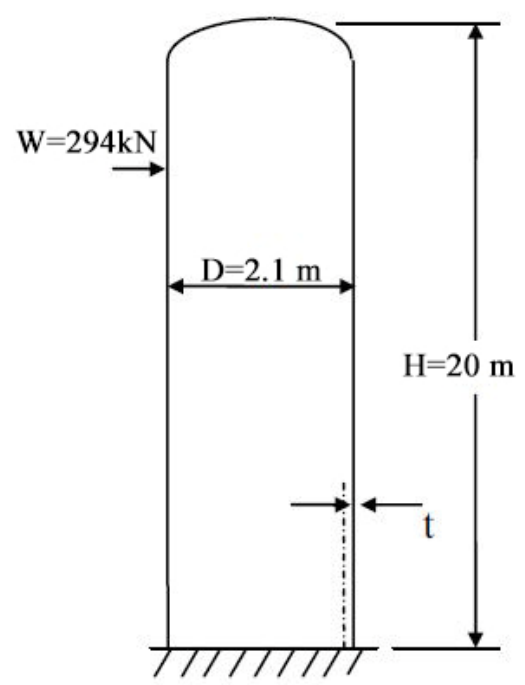

Figure 28. Uniform cylindrical column (After Reference [5], modified).

The fundamental period of the fixed-base structure is equal to $0.54 \mathrm{~s}$. Based on the response spectra obtained using the 1693 seismic input (Figure 26), a spectral acceleration of $0.99 \mathrm{~g}$ has been obtained, according to NTC 2018 [51], while lower values of $0.66 \mathrm{~g}$ (FF alignment) and $0.85 \mathrm{~g}$ (SSI alignment) have been found from FEM numerical analysis. Therefore, for the period of the structure under consideration, the NTC 2018 [51] spectrum is more conservative. Moreover, the soil-structure interaction leads to a designed acceleration greater than that required in the FF condition due to the second period $\mathrm{T}=0.58 \mathrm{~s}$ in the SSI condition.

The period of the structure resting on the soil can be calculated as the ratio between the Fourier amplitude spectra computed at the top and at the bottom of the structure [41]. The resulting period of the structure, $\mathrm{T}_{\mathrm{STRU}}$, SSI, is equal to $0.95 \mathrm{~s}\left(\mathrm{f}_{\mathrm{STRU}, \mathrm{SSI}}=1.05 \mathrm{~Hz}\right)$. In this case, a spectral acceleration of $0.65 \mathrm{~g}$ has been obtained, according to NTC 2018 [51], while lower values of $0.37 \mathrm{~g}$ (FF alignment) and $0.40 \mathrm{~g}$ (SSI alignment) have been found from FEM numerical analysis. SSI has beneficial effects because the spectral accelerations are lower than those required for the period of the fixed-base structure.

Figure 29 shows the distribution of the bending moment along the plate at the end of the dynamic phase using the 1693 seismic input. The results of the moment distribution indicate that the maximum bending moments are distributed based on the pile heads.

The seismic response of the piled foundation has been further examined in terms of the dynamic pile bending moment. In fact, the seismic response of piles involves the inertial interaction between the structure and the piles as well as the kinematic interaction between the piles and the soil foundation. Thus, for pile foundations built in seismic areas, the demands to sustain load and deformation during an earthquake will likely be the most severe in their design life.

There is evidence that, in the past, pile groups have undergone lateral translations severe enough to cause loss of bearing support for superstructures and structural failure [54-60]. 


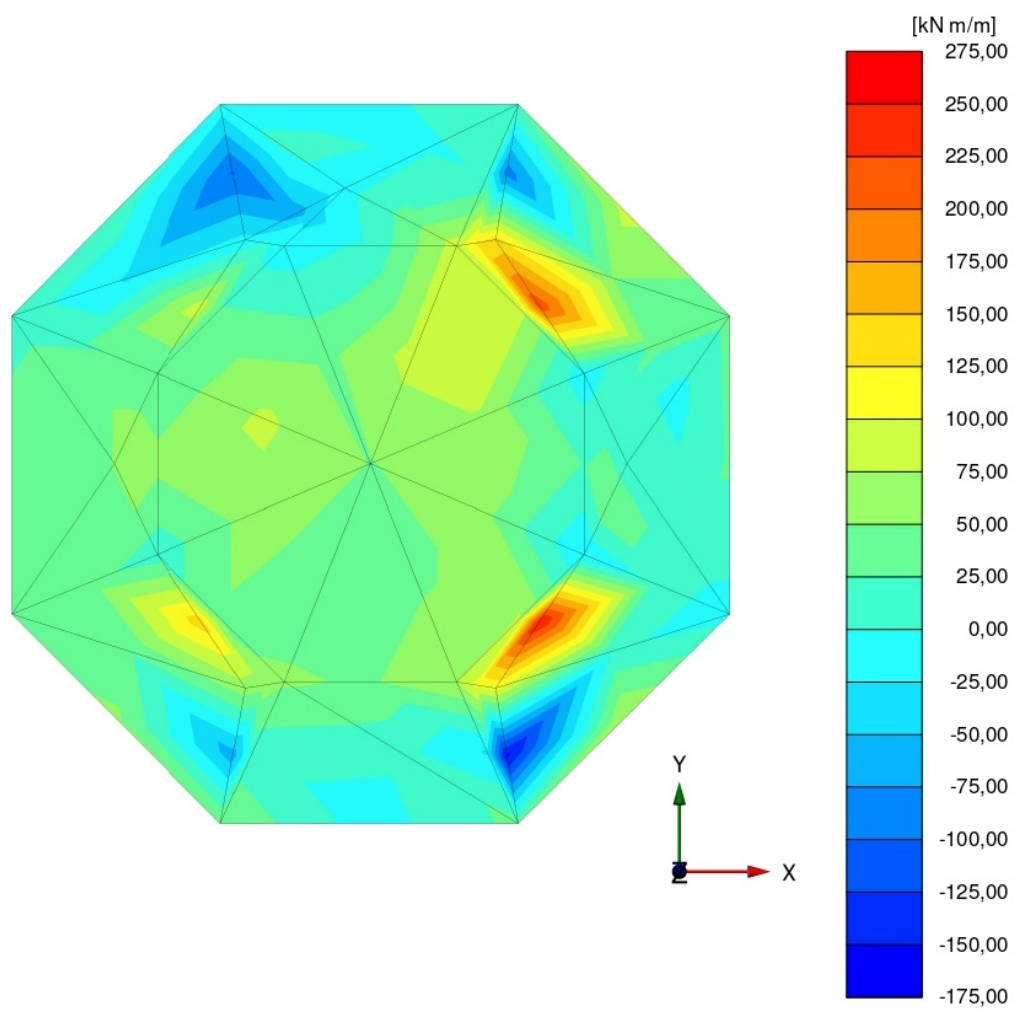

Figure 29. Bending moments along the plate at the end of the dynamic phase using the 1693 seismic input.

During an earthquake there are two sources of loading on piles: (i) "inertial" loading of the pile head caused by the lateral forces imposed on the superstructure, and (ii) "kinematic" loading along the length of the pile caused by the lateral soil movements developed during the earthquake, assuming zero inertia at the superstructure $[12,61,62]$

As a consequence, piles should be designed for the following two loading conditions:

(a) inertia forces on the superstructure transmitted on the heads of the piles in the form of axial and horizontal forces and moment;

(b) soil deformations arising from the passage of seismic waves, which impose curvatures and, thereby, a lateral strain on the piles along their whole length.

Kinematic bending moments are significant especially with regard to stiff pile caps and soil layer interfaces characterized by a contrast of stiffness.

While there is ample experience for carrying out the equivalent static analysis for inertial loading (type (a)), no specific method or procedures are available to predict deformations and the bending moment for kinematic loading (type (b)).

With this aim, the computed bending moments distribution along the pile length are reported in Figure 30, for pile 4, as an example. In this case, the numerical simulation provides the bending moment distribution along the pile length related to inertial loading and kinematic lateral soil movements. For the 1693 seismic input, a bending moment of $134 \mathrm{kNm}$ can be observed at the pile head, characterized by a fixed connection between the plate and the piles head.

The maximum bending moment $(365 \mathrm{kNm})$ occurs at a depth of about $12.5 \mathrm{~m}$, reducing progressively to zero close to the piles tip. Similar trends are obtained using the 1990 and 2012 seismic inputs (Figure 30). These maximum bending moments can result in a kinematic interaction effect between the piles and the soil.

Kinematic pile bending tends to be amplified close to the interface (Figure 31) between the softer alluvial deposits and stiffer sandy clay (Table 3), which typically occurs due to a kinematic interaction effect [12]. 


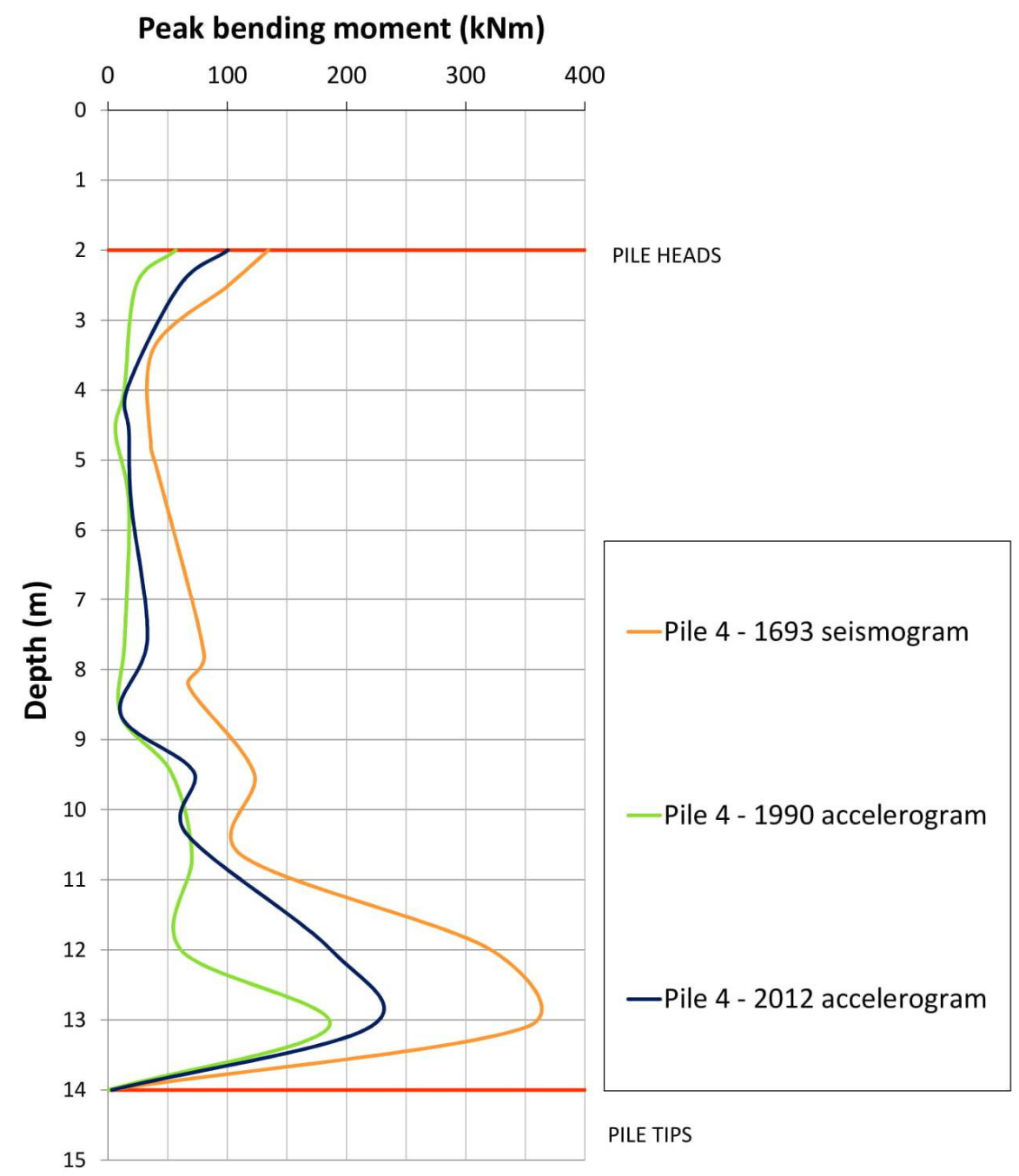

Figure 30. Peak bending moments along pile 4, using the 1693, 2012, and 1990 seismic inputs.

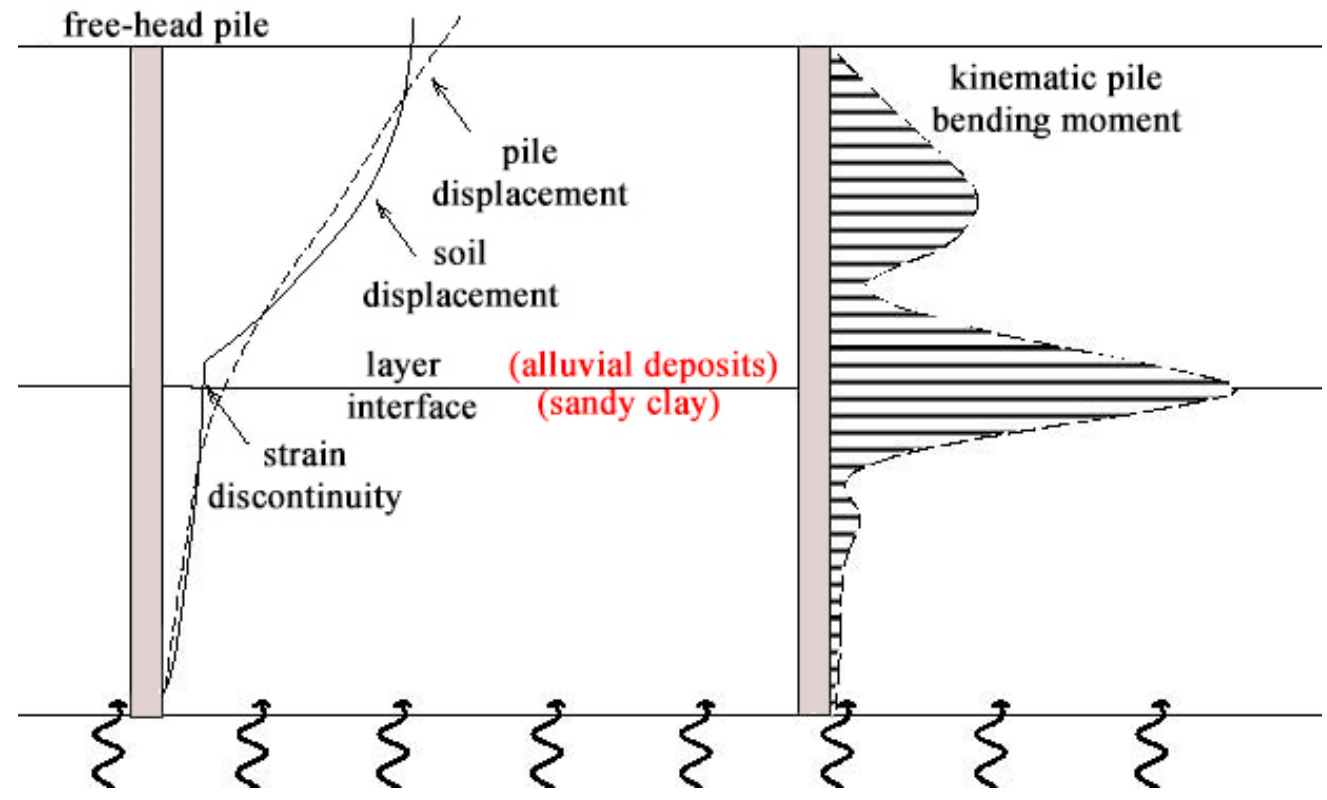

Figure 31. Kinematic bending of a free-head pile in a two-layer profile (After Castelli et al. [12], modified). 
Finally, the stress state in the finite element model along a vertical cross section of the mesh at the end of the dynamic phase (for the 1693 seismic input) is displayed in Figure 32 in terms of mean total stress $p=\left(\sigma_{1}+\sigma_{2}+\sigma_{3}\right) / 3$, where $\sigma_{1}$ is the largest compressive principal stress and $\sigma_{3}$ is the smallest compressive principal stress $\left(\sigma_{1} \leq \sigma_{2} \leq \sigma_{3}\right)$. The variation of the stress state in the area close to the pile tips is likely related to a more pronounced interaction effect of the piles in the group with respect to the fixed connection of the top.
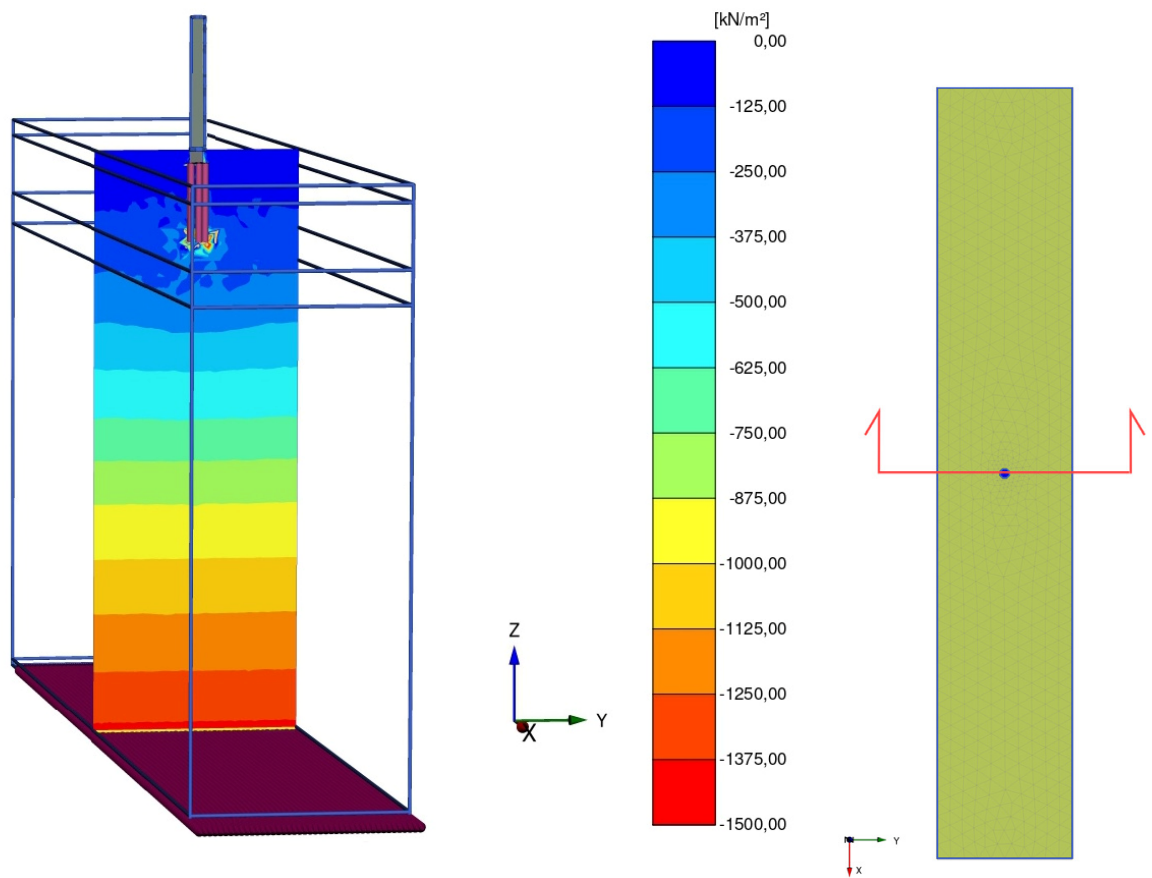

Figure 32. Mean total stresses $\mathrm{p}=\left(\sigma_{1}+\sigma_{2}+\sigma_{3}\right) / 3$ at the end of the dynamic phase (for the 1693 seismic input), $\sigma_{1}$ being the largest compressive principal stress and $\sigma_{3}$ being the smallest compressive principal stress $\left(\sigma_{1} \leq \sigma_{2} \leq \sigma_{3}\right)$.

In the literature, only a limited number of studies have been carried out considering deep foundations embedded in multi-layered soil profiles. This is likely due to the high computational cost and the skills required to carry out numerical simulation using Finite Element analysis. Therefore, in our opinion, a study like the one proposed in the paper should be welcomed. In fact, FEM is a very viable method to capture the real behaviour of a soil-pile interaction in the three-dimensional domain and a continuum-based analysis can be used to simulate, in a realistic way, the kinematic pile behaviour under a seismic excitation.

\section{Conclusions}

In the city of Augusta, located in Southeastern Sicily (Italy) and characterized by a high seismic hazard, there are important, industrial, petrochemical facilities. They are classified with high risk according to the Seveso III Directive based on major-accident hazards involving dangerous substances [30].

The seismic vulnerability of petrochemical facilities is often analyzed by applying codes and guidelines developed primarily in the design of new and existing buildings. On the contrary, the evaluation of seismic safety of these facilities requires specific evaluation issues.

The idea of the proposed study is to provide a practical guidance to people involved in the seismic design of petrochemical facilities, as a best practice for the vulnerability evaluation. It is intended to serve the following objectives: 
- to better understand the intent behind certain provisions of seismic design codes, so that they can be more properly and uniformly applied to structures and systems typically found in petrochemical facilities;

- to provide background information on technical areas that are related to the seismic evaluation of petrochemical facilities;

- to provide specific guidance to the seismic evaluation of petrochemical facilities;

- to provide practical analytical guidance specifically applicable to petrochemical facilities.

With this aim, the dynamic response of a fully-coupled, soil-structure system has been carried out by means of a PLAXIS 3D numerical code.

For the site characterization of soil, deep site investigations have been performed. The response of the system has been analyzed, considering and not considering the SoilStructure Interaction (SSI), which demonstrates that the SSI can lead to alterations of the free-field motion.

The results of the numerical modeling have also been compared with those suggested by the Italian Technical Regulations [51]. The findings of this study show that many factors have to be considered on the seismic design of new structures and/or apparatuses or retrofitting of existing ones. The main considerations can be summarized as follows.

- The FEM analyses show a strong amplification in the last $20 \mathrm{~m}$ up to ground level for both Free-Field (FF) and soil-structure interaction (SSI) alignments using the 2012 and 1693 seismic inputs. The 1990 accelerogram induces a larger amplification in the upper $10 \mathrm{~m}$ of soil. Moreover, the presence of the structure generates a lower amplification as compared to the free-field condition;

- The influence of the soil-structure interaction is also indicated by reducing the maximum spectral acceleration at the main period of $\mathrm{T}=0.25 \mathrm{~s}$. However, a second, less important, period $\mathrm{T}=0.58 \mathrm{~s}$, corresponding to a spectral acceleration of $1.0 \mathrm{~g}$, can be observed in the SSI condition using the 1693 seismogram;

- Taking into account the SSI effects, a beneficial effect can be observed. The spectral accelerations obtained when considering the structure resting on the soil are lower than what is required for fixed-base structure's period;

- The main resulting frequencies for the SSI condition are equal to: $\mathrm{f}_{\mathrm{SSI}}(\mathrm{I})=2.1 \mathrm{~Hz}$ and $\mathrm{f}_{\mathrm{SSI}}(\mathrm{II})=3.7 \mathrm{~Hz}$. They are far from the frequency of the structure $\mathrm{f}_{\mathrm{STRU}}, \mathrm{SSI}=1.05 \mathrm{~Hz}$.

- The soil amplification factors R derived for SSI and FF alignments using the 1990 and 1693 input motions are greater than the amplification value provided by the Italian Technical Code [51]. Instead, lower values are obtained using the 2012 accelerogram. The comparison between the elastic response spectra obtained by numerical analyses using the 1693 and 2012 seismic inputs and the same provided by NTC 2018 shows that FEM spectral accelerations are lower than those given by NTC 2018 for periods greater that $0.30 \mathrm{~s}$. In particular, for the period of the structure under consideration $\left(T_{\text {STRU,SSI }}=0.95 \mathrm{~s}\right)$, the spectral acceleration given by NTC 2018 is equal to $0.65 \mathrm{~g}$.

- To investigate the effect of the kinematic and inertial interaction on pile bending moments, the distribution of the peak pile bending moments has been studied. It can be observed that the maximum bending moments occur at a depth of about $12.5 \mathrm{~m}$, and it can result in a kinematic interaction effect between the piles and the surrounding soil.

As a consequence of this last indication, it can be stated that, if kinematic effects are ignored and only inertial effects are considered, the maximum bending moment distribution along the piles length can be underestimated.

Author Contributions: Conceptualization, F.C.; Methodology, S.G., V.L. and M.S.V.S.; Software, M.S.V.S.; Validation, S.G., V.L. and M.S.V.S.; Formal analysis, M.S.V.S.; Investigation, V.L.; Resources, F.C.; Data Curation, S.G., V.L. and M.S.V.S.; Writing-Original Draft Preparation S.G., V.L. and M.S.V.S.; Writing—Review and Editing S.G., V.L. and M.S.V.S.; Visualization, S.G. and V.L.; Supervision, F.C.; Project Administration, F.C.; Funding acquisition, F.C. All authors have read and agreed to the published version of the manuscript. 
Funding: This research work was funded by the MIUR (Ministry of Education, Universities and Research [Italy]) through the project entitled "eWAS".

Institutional Review Board Statement: Not applicable.

Informed Consent Statement: Not applicable.

Data Availability Statement: Not applicable.

Acknowledgments: The authors acknowledge the financial support received from the MIUR (Ministry of Education, Universities and Research [Italy]) through the project entitled "eWAS: an early Warning System for cultural-heritage" (Project code: ARS01_00926/CUP J66C18000390005), financed with the PNR 2015-2020 (National Research Program). The authors authorize the MIUR to reproduce and distribute reprints for Governmental purposes, notwithstanding any copyright notations thereon. Any opinions, findings, and conclusions or recommendations expressed in this material are those of the authors and do not necessarily reflect the views of the MIUR.

Conflicts of Interest: The authors declare no conflict of interest.

\section{References}

1. Paolacci, F.; Giannini, R.; De Angelis, M. Analysis of the seismic risk of major-hazard industrial plants and applicability of innovative seismic protection systems. Petrochemicals 2012. [CrossRef]

2. Kalantari, A.; Abdi, D.; Feshki, B.A. Seismic fragility assessment of equipment and support structure in a unit of a petrochemical plant. SN Appl. Sci. 2020, 2, 1345. [CrossRef]

3. Romeo, R.W. Seismic Risk Analysis of an Oil-gas Storage Plant. In Seismic Design of Industrial Facilities: Proceedings of the on Seismic Design of Industrial Facilities (SeDIF-Conference); Klinkel, S., Butenweg, C., Lin, G., Holtschoppen, B., Eds.; Springer: Berlin/Heidelberg, Germany, 2014; pp. 17-26.

4. Paolacci, F.; Giannini, R.; De Angelis, M. Seismic vulnerability of major-hazard industrial plants and applicability of innovative seismic protection systems for its reduction. In Proceedings of the 11th World Conference on Seismic Isolation, Energy Dissipation and Active Vibration Control of Structures, Guangzhou, China, 17-21 November 2009.

5. American Society of Civil Engineers (ASCE). Guidelines for Seismic Evaluation and Design of Petrochemical Facilities, 2nd ed.; ASCE: Reston, Virginia, 2011. [CrossRef]

6. Ferraro, A.; Grasso, S.; Maugeri, M.; Totani, F. Seismic response analysis in the southern part of the historic centre of the City of L'Aquila (Italy). Soil Dyn. Earthq. Eng. 2016, 88, 256-264. [CrossRef]

7. Ferraro, A.; Grasso, S.; Massimino, M.R. Site effects evaluation in Catania (Italy) by means of 1-D numerical analysis. Ann. Geophys. 2018, 61. [CrossRef]

8. Grasso, S.; Massimino, M.R.; Sammito, M.S.V. New Stress Reduction Factor for Evaluating Soil Liquefaction in the Coastal Area of Catania (Italy). Geosciences 2021, 11, 12. [CrossRef]

9. Zhang, W.; Esmaeilzadeh Seylabi, E.; Taciroglu, E. An ABAQUS toolbox for soil-structure interaction analysis. Comput. Geotech. 2019, 114, 103143. [CrossRef]

10. Seylabi, E.E.; Jeong, C.; Dashti, S.; Hushmand, A.; Taciroglu, E. Seismic response of buried reservoir structures: a comparison of numerical simulations with centrifuge experiments. Soil Dyn. Earthq. Eng. 2018, 109, 89-101. [CrossRef]

11. Massimino, M.R.; Abate, G.; Corsico, S.; Louarn, R. Comparison Between Two Approaches for Non-linear FEM Modelling of the Seismic Behaviour of a Coupled Soil-Structure System. Geotech. Geol. Eng. 2019, 37, 1957-1975. [CrossRef]

12. Castelli, F.; Maugeri, M.; Mylonakis, G. Numerical analysis of kinematic soil-pile interaction. In Proceedings of the MERCEA 2008, Seismic Engineering International Conference Commemorating the 1908 Messina and Reggio Calabria Earthquake, Reggio Calabria/Messina, Italy, 8-11 July 2008; Volume 1, pp. 618-625. [CrossRef]

13. Kavitha, P.E.; Beena, K.S.; Narayanan, K.P. Numerical Investigations on the Influence of Soil Structure Interaction in the Dynamic Response of SDOF System. Procedia Technol. 2016, 25, 178-185. [CrossRef]

14. Deghoul, L.; Gabi, S.; Hamrouni, A. The influence of the soil constitutive models on the seismic analysis of pile-supported wharf structures with batter piles in cut-slope rock dike. Studia Geotech. Mech. 2020, 42, 191-209. [CrossRef]

15. Cavallaro, A.; Castelli, F.; Ferraro, A.; Grasso, S.; Lentini, V. Site Response Analysis for the Seismic Improvement of a Historical and Monumental Building: The Case Study of Augusta Hangar. Bull. Eng. Geol. Environ. 2018, 77, 1217-1248. [CrossRef]

16. Di Martire, D.; Ascione, A.; Calcaterra, D.; Pappalardo, G.; Mazzoli, S. Quaternary deformation in SE Sicily: Insights into the life and cycles of forebulge fault systems. Lithosphere 2015, 7, 519-534. [CrossRef]

17. Locati, M.; Camassi, R.; Rovida, A.; Ercolani, E.; Bernardini, F.; Castelli, V.; Caracciolo, C.H.; Tertulliani, A.; Rossi, A.; Azzaro, R.; et al. Database Macrosismico Italiano (DBMI15); Versione 3.0; Istituto Nazionale di Geofisica e Vulcanologia (INGV): Catania, Italy, 2021. [CrossRef]

18. Cavallaro, A.; Massimino, M.R.; Maugeri, M. Noto Cathedral: Soil and foundation investigation. Constr. Build. Mater. J. 2003, 17, 533-541. [CrossRef] 
19. Grasso, S.; Maugeri, M. Seismic Microzonation Studies for the City of Ragusa (Italy). Soil Dyn. Earthq. Eng. 2014, 56, 86-97. [CrossRef]

20. Castelli, F.; Cavallaro, A.; Grasso, S. SDMT soil testing for the local site response analysis. In 1st IMEKO TC4 International Workshop on Metrology for Geotechnics; MetroGeotechnics: Benevento, Italy, 2016; pp. 143-148.

21. Maugeri, M.; Grasso, S. Liquefaction potential evaluation at Catania Harbour (Italy). WIT Trans Built Environ. 2013, 69-81. [CrossRef]

22. Barbano, M.S.; Rigano, R.; Cosentino, M.; Lombardo, G. Seismic history and hazard in some localities of south-eastern Sicily. Boll. Geof. Teor. Appl. 2001, 42, 107-120.

23. Maugeri, M.; Castelli, F. Post-earthquake analysis for a seismic retrofitting: the case history of a piled foundation in Augusta (Italy). Chapter: perspectives on earthquake geotechnical engineering. Geotech. Geol. Earthq. Eng. 2015, 37, 415-441.

24. Guidoboni, E.; Ferrari, G.; Mariotti, D.; Comastri, A.; Tarabusi, G.; Sgattoni, G.; Valensise, G. CFTI5Med, Catalogue of Strong Earthquakes in Italy (461 B.C.-1997) and Mediterranean Area (760 B.C.-1500); Istituto Nazionale di Geofisica e Vulcanologia (INGV): Catania, Italy, 2018. [CrossRef]

25. Guidoboni, E.; Ferrari, G.; Tarabusi, G.; Sgattoni, G.; Comastri, A.; Mariotti, D.; Ciuccarelli, C.; Bianchi, M.G.; Valensise, G. CFTI5Med, the new release of the catalogue of strong earthquakes in Italy and in Mediterranean area. Sci. Data 2019, 80. [CrossRef]

26. Castelli, F.; Lentini, V.; Grasso, S. Recent developments for the seismic risk assessment. Bull. Earth. Eng. 2017, 15, 5093-5117. [CrossRef]

27. Castelli, F.; Cavallaro, A.; Ferraro, A.; Grasso, S.; Lentini, V.; Massimino, M. Dynamic characterisation of a test site in Messina (Italy). Ann. Geophys. 2018, 61, SE222. [CrossRef]

28. Castelli, F.; Cavallaro, A.; Ferraro, A.; Grasso, S.; Lentini, V.; Massimino, M.R. Static and dynamic properties of soils in Catania (Italy). Ann. Geophys. 2018, 61, SE221. [CrossRef]

29. Ciancimino, A.; Lanzo, G.; Alleanza, G.A.; Amoroso, S.; Bardotti, R.; Biondi, G.; Cascone, E.; Castelli, F.; Di Giulio, A.; D’onofrio, A.; et al. Dynamic characterization of fine-grained soils in Central Italy by laboratory testing. Bull. Earth. Eng. 2020, 18, 5503-5531. [CrossRef]

30. European Parliament and of the Council. Directive 2012/18/EU of the European Parliament and of the Council on Control of MajorAccident Hazards Involving Dangerous Substances Amending and Subsequently Repealing Council Directive 96/82/EC; European Parliament and of the Council: Brussels, Belgium, 2012.

31. Giannelli, G.; Grillone, G.; Muratore, A.; Nastasi, V.; Sferruzza, G. Earthquake Natech Risk: Index Method for critical Plants covered by Seveso III Directive. In Proceedings of the 30th European Safety and Reliability Conference and the 15th Probabilistic Safety Assessment and Management Conference, Venice, Italy, 21-26 June 2020.

32. Salzano, E.; Garcia Agreda, A.; Di Carluccio, B.; Fabbrocino, G. Risk assessment and early warning systems for industrial facilities in seismic zones. Rel. Eng. Syst. Saf. 2009, 94, 1577-1584. [CrossRef]

33. Marzorati, S.; Fiorini, E.; Ameri, G.; Onida, M.; Pacor, F. Rapporti spettrali HVSR in aree densamente industrializzate: ricostruzione di una superficie pleistocenica profonda al di sotto del polo petrolchimico di Priolo Gargallo (SR). In Proceedings of the 27 Convegno GNGTS, Sessione 2.2, Trieste, Italy, 6-8 October 2008.

34. Fiorini, E.; Onida, M.; Borzi, B.; Pacor, F.; Luzi, L.; Meletti, C.; D’Amico, V.; Marzorati, S.; Ameri, G. Microzonation Study for an industrial site in southern Italy. In Proceedings of the 14th World Conference on Earthquake Engineering, Beijing, China, 12-17 October 2008.

35. Tortorici, L. Geologia delle aree urbane della Sicilia orientale, in Decanini e Panza. In Scenari di Pericolosità Sismica ad Augusta, Siracusa e Noto; CNR-GNDT: Roma, Italy, 2000; pp. 43-54.

36. Carbone, S. Augusta: Foglio 641: Note illustrative Della Carta Geologica d'Italia Alla Scala 1:50.000; Regione Sicilia: Ispra, Roma, Italy, 2011.

37. Kuhlemeyer, R.L.; Lysmer, J. Finite element method accurancy for wave propagation problems. J. Soil Mech. Found. Devision 1973, 99, 421-427. [CrossRef]

38. Galavi, V.; Petalas, A.; Brinkgreve, R.B.J. Finite element modelling of seismic liquefaction in soils. Geotech. Eng. J. SEAGS AGSSEA 2013, 44, 55-64.

39. PLAXIS 3D. Scientific Manual. 2018. Available online: https://communities.bentley.com/products/geotech-analysis/w/plaxissoilvision-wiki/50826/manuals-archive---plaxis (accessed on 12 December 2020).

40. Joyner, W.B.; Chen, A.T.F. Calculation of non linear ground response in earthquake. Bull. Seismol. Soc. Am. 1975, 65, $1315-1336$.

41. Massimino, M.R.; Abate, G.; Grasso, S.; Pitilakis, D. Some aspects of DSSI in the dynamic response of fully-coupled soil-structure systems. Riv. Ital. Geotec. 2019, 44-70.

42. EC8-Part 5. Design of Structures for Earthquake Resistance-Part 5: Foundations, Retaining Structures and Geotechnical Aspects; ENV 1998; Europen Committee for Standard: Brussels, Belgium, 2003.

43. Sadek, M.; Shahrour, I. A three dimensional embedded beam element for reinforced geomaterials. Int. J. Num. Anal. Meth. Geomech. 2004, 28, 931-946. [CrossRef]

44. Smulders, C.M.; Hosseini, S.; Brinkgreve, R.B. Improved embedded beam with interaction surface, ECSMGE 2019. In Proceedings of the XVII European Conference on Soil Mechanics and Geotechnical Engineering, Reykjavik, Iceland, 1-6 September 2019.

45. Brinkgreve, R.B.J.; Engin, E.; Swolfs, W.M. Plaxis 3D Manual. 2015. Available online: https://communities.bentley.com/products/ geotech-analysis/w/plaxis-soilvision-wiki/50826/manuals-archive---plaxis (accessed on 10 October 2020). 
46. PLAXIS 3D. Reference Manual. 2018. Available online: https://communities.bentley.com/products/geotech-analysis/w/plaxissoilvision-wiki/50826/manuals-archive---plaxis (accessed on 18 January 2021).

47. Lődör, K.; Móczár, B. Finite element modelling of rigid inclusion ground improvement. In Proceedings of the 9th European Conference on Numerical Methods in Geotechnical Engineering, Porto, Portugal, 25-27 June 2018.

48. Grasso, S.; Laurenzano, G.; Maugeri, M.; Priolo, E. Seismic response in Catania by different methodologies. In Advances in Earthquake Engineering; Publisher: Billerica, MA, USA, 2005; Volume 14, pp. 63-79.

49. Laurenzano, G.; Priolo, E.; Klinc, P.; Vuan, A. Near fault earthquake scenarios for the February 20, $1818 \mathrm{M}=6.2$ "Catanese" event. In Proceedings of the Fourth International Conference on Computer Simulation in Risk Analysis and Hazard Mitigation: "Risk Analysis 2004", Rhodes, Greece, 27-29 September 2004; pp. 81-91.

50. Priolo, E. 2-D spectral element simulations of destructive ground shaking in Catania (Italy). J. Seismol. 1999, 3, 289-309. [CrossRef]

51. NTC D.M. New Technical Standards for Buildings. 2018. Available online: https://www.gazzettaufficiale.it/eli/gu/2018/02/20/4 2/so/8/sg/pdf (accessed on 1 February 2021).

52. Fioravante, V.; Giretti, D.; Abate, G.; Aversa, S.; Boldini, D.; Capilleri, P.; Cavallaro, A.; Chamlagain, D.; Crespellani, T.; Dezi, F.; et al. Earthquake geotechnical engineering aspects of the 2012 Emilia-Romagna earthquake (Italy). In Proceedings of the Seventh International Conference on Case Histories in Geotechnical Engineering and Symposium in Honor of Clyde Baker, Chicago, IL, USA, 29 April-4 March 2013.

53. Boschi, E.; Basili, A. Contributi allo studio del terremoto della Sicilia orientale del 13 Dicembre 1990; Istituto Nazionale di Geofisica: Rome, Italy, 1991.

54. Okamoto, S. An Introduction to Earthquake Engineering, 2nd ed.; University of Tokyo Press: Tokyo, Japan, 1983.

55. Nishizawa, T.; Tajiri, S.; Kawamura, S. Excavation and response analysis of a damaged rc pile by liquefaction. In Proceedings of the 8th World Conference on Earthquake Engineering, San Francisco, CA, USA, 1 January 1984; pp. 593-600.

56. EEFIT. The Mexican Earthquake of 19 September 1985; Institution of Civil Engineers (ICE): London, UK, 1986.

57. Mizuno, H. Pile damage during earthquake in Japan (1923-1983). In Dynamic Response of Pile Foundations: Experiments, Observation and Analysis; Nogami, T., Ed.; ASCE: New York, NY, USA, 1987; pp. 53-78.

58. Mizuno, H.; Jiba, M.; Hirade, T. Pile damage during 1995 Hyougoken-Nanbu earthquake in Japan. In Proceedings of the 11th World Conference on Earthquake Engineering, Acapulco, Mexico, 23-28 June 1996.

59. Tokimatsu, K.; Mizuno, H.; Kakurai, M. Building damage associated with geotechnical problems. In Soils and Foundations, Special Issue Geotechnical aspects of the January 17, 1995 Hyogoken-Nambu Earthquake; Japanese Geotechnical Society: Tokyo, Japan, 1996.

60. Nikolaou, S.; Mylonakis, G.; Gazetas, G.; Tazoh, T. Kinematic pile bending during earthquakes: analysis and field measurements. Geotechnique 2001, 51, 425-440. [CrossRef]

61. Castelli, F.; Maugeri, M. Post-earthquake analysis of a piled foundation. J. Geotech. Geoenvironmental Eng. ASCE 2013, 139, 1822-1827. [CrossRef]

62. Castelli, F.; Lentini, V. Monitoring of Full Scale Diaphragm Wall for a Deep Excavation. In Proceedings of the 1st IMEKO TC-4 International Workshop on Metrology for Geotechnics, Benevento, Italy, 17-18 March 2016; pp. 103-108. 